OPEN ACCESS

Check for updates

\section{Association between the reproductive health of young women and cardiovascular disease in later life: umbrella review}

\author{
Kelvin Okoth, ${ }^{1}$ Joht Singh Chandan, ${ }^{1}$ Tom Marshall, ${ }^{1}$ Shakila Thangaratinam, ${ }^{1,2}$ G Neil Thomas, ${ }^{1}$ \\ Krishnarajah Nirantharakumar, ${ }^{1,3,4}$ Nicola J Adderley ${ }^{1}$
}

${ }^{1}$ Institute of Applied Health

Research, University of

Birmingham, Birmingham, UK

${ }^{2}$ Women's Health Research Unit, Barts and The London School of Medicine and Dentistry, Queen

Mary University of London,

London, UK

${ }^{3}$ Institute of Metabolism and Systems Research, University of Birmingham, Edgbaston, Birmingham B15 2TT, UK

${ }^{4}$ Centre for Endocrinology, Diabetes and Metabolism, Birmingham Health Partners, Birmingham, UK

Correspondence to:

K Nirantharakumar

K.Nirantharan@bham.ac.uk

(or @Nirantharakumar on Twitter:

ORCID 0000-0002-6816-1279)

Additional material is published online only. To view please visit

the journal online.

Cite this as: $B M J$ 2020;371:m3502

http://dx.doi.org/10.1136/bmj.m3502

Accepted: 24 August 2020

\section{ABSTRACT}

OBJECTIVE

To consolidate evidence from systematic reviews and meta-analyses investigating the association between reproductive factors in women of reproductive age and their subsequent risk of cardiovascular disease.

DESIGN

Umbrella review.

DATA SOURCES

Medline, Embase, and Cochrane databases for systematic reviews and meta-analyses from inception until 31 August 2019.

\section{REVIEW METHODS}

Two independent reviewers undertook screening, data extraction, and quality appraisal. The population was women of reproductive age. Exposures were fertility related factors and adverse pregnancy outcomes. Outcome was cardiovascular diseases in women, including ischaemic heart disease, heart failure, peripheral arterial disease, and stroke.

RESULTS

32 reviews were included, evaluating multiple risk factors over an average follow-up period of 7-10 years. All except three reviews were of moderate quality. A narrative evidence synthesis with forest plots and tabular presentations was performed. Associations for composite cardiovascular disease were: twofold for pre-eclampsia, stillbirth, and preterm birth; 1.5-1.9-fold for gestational hypertension, placental abruption, gestational diabetes, and premature ovarian insufficiency; and less than 1.5-fold for early menarche, polycystic ovary syndrome, ever parity, and early menopause. A longer length of breastfeeding was associated with a reduced risk of cardiovascular disease. The associations for ischaemic heart disease were twofold or greater for pre-eclampsia, recurrent pre-eclampsia, gestational diabetes, and preterm

\section{WHAT IS ALREADY KNOWN ON THIS TOPIC}

Risk factors specific to women are associated with cardiovascular disease Individual reviews assessing the implications of these risk factors for cardiovascular disease have been published

Clarity on the quality of the evidence is lacking and on how the findings can be translated into public health and clinical practice

\section{WHAT THIS STUDY ADDS}

This study provides a comprehensive list of factors related to reproduction and adverse pregnancy outcomes and their association with cardiovascular disease The review provides clarity on the quality of the evidence, identifies gaps in evidence and practice, and provides recommendations that could be incorporated into guidelines birth; 1.5-1.9-fold for current use of combined oral contraceptives (oestrogen and progesterone), recurrent miscarriage, premature ovarian insufficiency, and early menopause; and less than 1.5-fold for miscarriage, polycystic ovary syndrome, and menopausal symptoms. For stroke outcomes, the associations were twofold or more for current use of any oral contraceptive (combined oral contraceptives or progesterone only pill), pre-eclampsia, and recurrent pre-eclampsia; 1.5-1.9-fold for current use of combined oral contraceptives, gestational diabetes, and preterm birth; and less than 1.5-fold for polycystic ovary syndrome. The association for heart failure was fourfold for pre-eclampsia. No association was found between cardiovascular disease outcomes and current use of progesterone only contraceptives, use of non-oral hormonal contraceptive agents, or fertility treatment.

\section{CONCLUSIONS}

From menarche to menopause, reproductive factors were associated with cardiovascular disease in women. In this review, presenting absolute numbers on the scale of the problem was not feasible; however, if these associations are causal, they could account for a large proportion of unexplained risk of cardiovascular disease in women, and the risk might at an early stage in the life of women might facilitate the initiation of strategies to modify potential risks. Policy makers should consider incorporating reproductive risk factors as part of the assessment of cardiovascular risk in clinical guidelines.

SYSTEMATIC REVIEW REGISTRATION

PROSPERO CRD42019120076.

\section{Introduction}

Globally, one third, or 17.9 million, of total annual deaths are attributable to cardiovascular disease. ${ }^{1}$ The incidence of cardiovascular disease has declined since the middle of the last century, but less so in women than in men. In developed countries, ${ }^{2-4}$ the incidence of cardiovascular disease has declined in older age groups $(\geq 55)$, but has stagnated or increased in adults aged less than $55 .^{35}$ For instance, in the United States, the proportion of hospital admissions for acute myocardial infarction for adults aged less than 55 rose from 27\% between 1995 and 1999 to 32\% between 2010 and $2014 .^{6}$ The greatest increases were recorded in women aged 35-54. ${ }^{6}$ In Western Australia, between 1996 and 2007, in adults aged 35-54, hospital admissions for acute myocardial infarctions increased by $4 \%$ in women but decreased by $0.2 \%$ in men. ${ }^{4}$ Other temporal trend analyses have recorded similar increases in women aged 30-54. ${ }^{6-9}$ be modifiable. Identifying reproductive risk factors 
Although many commonalities exist, several differences between men and women in terms of risk factors for cardiovascular disease are apparent. Traditional risk factors for cardiovascular disease, such as smoking and diabetes, affect women more than men. ${ }^{10}{ }^{11}$ Beyond these traditional risk factors, risk factors specific to women, such as adverse pregnancy outcomes and fertility complications, are under recognised. ${ }^{12}$ Women experiencing adverse pregnancy outcomes and issues related to fertility have been shown to often have early manifestations of vascular changes. Endothelial dysfunction has been shown to be prevalent in women with a history of pre-eclampsia and recurrent pregnancy loss, and could remain beyond pregnancy complications, predisposing these women to further vascular complications and serving as a prognostic marker for future cardiovascular disease. ${ }^{13}$ Biochemical risk factors for cardiovascular disease, including raised concentrations of cholesterol, glucose, and triglycerides, have been shown to persist many years after a hypertensive disorder of pregnancy. ${ }^{14} \mathrm{~A}$ better understanding of associations with these risk factors could be explored in future research to identify areas of modifiable risk in women to reduce their long term risk of cardiovascular disease.

In developed countries, up to a third of parous women experience one or more adverse pregnancy outcomes, ${ }^{15}$ including hypertensive disorders of pregnancy, gestational diabetes mellitus, placental abruption, and low birth weight and preterm births. ${ }^{16}$ Reproductive risk factors are not limited to the obstetric period. Globally, up to $10 \%$ of women are diagnosed with secondary infertility. ${ }^{17}$ Common causes of secondary infertility, including polycystic ovary syndrome, premature ovarian insufficiency, endometriosis, and pelvic inflammatory disease, have been linked to an increased risk of cardiovascular disease. ${ }^{18-20}$ Also, early age at menarche, early menopause, and use of hormonal contraceptive agents are associated with risk of cardiovascular disease. ${ }^{21}$

In the past three decades, the prevalence of adverse pregnancy outcomes has increased in some developed countries. ${ }^{22-25}$ On average, young women could develop cardiovascular disease events as early as a decade after experiencing an adverse pregnancy outcome. ${ }^{2627}$ Young women who develop acute coronary syndromes have longer stays in hospital after admission, higher readmission rates, and higher mortality than men. ${ }^{72}$ Moreover, women with pre-eclampsia have six times the risk of readmission for acute coronary syndromes at one year and tend to present with a more serious type of myocardial infarction than women without pre-eclampsia. ${ }^{29}$ Prediction models for traditional risk factors for cardiovascular disease are less optimal in young adults. ${ }^{30}{ }^{31}$ Also, only $49 \%$ of primary care physicians in the US said they were confident in the assessment of the risk of cardiovascular disease in women. $^{32}$

Adverse pregnancy outcomes and cardiovascular disease share common (traditional) risk factors, including hypertension, hyperglycaemia, and obesity.
In a Norwegian cohort study, blood pressure and body mass index were linked to $77 \%$ of the excess risk of cardiovascular disease in women with hypertensive disorders of pregnancy. ${ }^{33} \mathrm{Up}$ to $15 \%$ of the risk of coronary heart disease in young women (aged <65) could not be accounted for by traditional risk factors. ${ }^{34}$

Several systematic reviews have looked at risk factors specific to women and cardiovascular disease but they evaluated different risk factors and different outcomes. An umbrella review is a review of existing systematic reviews and meta-analyses. ${ }^{35}$

The aim of the study was to conduct an umbrella review of systematic reviews evaluating the association between risk factors specific to women (adverse pregnancy outcomes and issues related to fertility) and cardiovascular disease outcomes. This umbrella review will provide decision makers with a consolidated source of high quality studies on this subject. This review will help in developing care pathways which consider a broader range of factors specific to women than are currently considered, in particular those risk factors that have the potential to be modified to reduce the risk of cardiovascular disease in women at high risk (such as those with pre-eclampsia, gestational diabetes, and polycystic ovary syndrome). ${ }^{36-38}$ The results of this review are presented by the exposure of interest (over the life course of women) and by cardiovascular outcome.

\section{Methods}

An umbrella review is a narrative compilation of evidence for several related clinical questions from multiple systematic reviews and meta-analyses into one usable document with text, tables, and graphics. It aims to examine what is known and not known, and then to propose recommendations for practice and research. ${ }^{39}$

Objective, population, exposures, and comparator In this review, we explored reproductive factors in women and their association with cardiovascular disease. The umbrella review followed the guidelines for Preferred Reporting Items for Systematic Reviews and Meta-Analyses (PRISMA), and the protocol was registered in PROSPERO (registration No CRD42019120076). The population included women of reproductive age.

Exposures were identified through a scoping search and consensus with an expert panel (clinicians and epidemiologists). The scoping search included search terms for women, cardiovascular disease, and risk factors, to identify relevant reproductive risk factors. These risk factors were related to fertility and adverse pregnancy outcomes. Factors related to fertility included: age at menarche; age at first pregnancy; age at first birth; early natural menopause; premature ovarian insufficiency; polycystic ovary syndrome; endometriosis; pelvic inflammatory disease; parity; gravidity; breastfeeding; use of hormonal contraceptive drugs; and fertility treatment. Adverse pregnancy outcomes included: pregnancy loss (miscarriage 
and stillbirth); hypertensive disorders of pregnancy (pre-eclampsia and gestational hypertension); low birth weight; small for gestational age; gestational diabetes; preterm birth; and placental abruption. The comparator group included women of reproductive age without the reproductive factor of interest (that is, controls or unexposed women).

\section{Outcomes}

Outcomes included: ischaemic heart disease; angina; myocardial infarction; coronary artery disease; cerebrovascular accident, including stroke and transient ischaemic attack; heart failure; peripheral arterial disease; and composite cardiovascular disease (ischaemic heart disease, cerebrovascular accident, heart failure, and peripheral arterial disease).

\section{Study design}

Systematic reviews or meta-analyses were included. A study qualified as a systematic review or metaanalysis if, at a minimum: it described the conduct of the systematic review in adequate detail; an attempt was made to identify all of the relevant primary studies in at least one database and a search strategy was provided; and it performed a quality appraisal of the primary studies included. ${ }^{40}$

Excluded were guidelines, narrative reviews, literature reviews, genetic studies, reviews looking at atherosclerosis or venous thromboembolism as an outcome, and reviews assessing the association between hormonal replacement treatment and cardiovascular disease.

\section{Search strategy}

Medline, Embase, and the Cochrane Database of Systematic Reviews were searched from inception until 31 August 2019 without language restrictions. The search strategy was developed around the key terms: menarche, OR hormonal contraceptives, OR polycystic ovary syndrome, OR menopause, OR endometriosis, OR hypertensive disorders of pregnancy, OR gestational diabetes, OR miscarriage, OR stillbirth, OR placental abruption, OR low birth weight, OR preterm birth, AND cardiovascular disease. The results were limited to systematic reviews and meta-analyses with a search filter. ${ }^{41}$ Reference lists of eligible reviews and meta-analyses were searched for additional citations. Appendix 1 provides a detailed search strategy for the Medline database. This strategy was adapted for searching Embase and the Cochrane Database of Systematic Reviews.

\section{Study selection and data extraction}

Two reviewers (KO and JSC) independently carried out the study selection and data extraction from the eligible studies. Data extracted included: author, year of publication, number of participants, number and type of studies included, appraisal instrument used, method of analysis, outcomes assessed, heterogeneity, and findings. The study used the data extraction form recommended by the Joanna Briggs Institute (appendix 2). ${ }^{42}$

\section{Quality assessment}

The online AMSTAR 2 (A MeaSurement Tool to Assess systematic Reviews) checklist was used to assess methodological quality and assign an overall rating for the reviews included. ${ }^{43}$ Two reviewers (KO and JSC) rated the methodological quality of the reviews with the AMSTAR 2 quality appraisal instrument. ${ }^{44}$ In the case of disagreements and failed consensus, a decision was reached by consulting a third reviewer (NJA).

The AMSTAR 2 quality assessment tool is a 16 item or domain checklist. Seven of these items are considered critical. Shortcomings in any of the critical domains could affect the overall validity of a review. The domains considered critical are: registration of the protocol before starting the review; conduct of an adequate search of the literature; providing justification for the exclusion of individual studies; satisfactory assessment of risk of bias in the studies included in the review; use of appropriate statistical methods in performing a meta-analysis; accounting for risk of bias when interpreting the results; and evaluation of the presence and effect of publication bias. $^{44}$

\section{Overlapping and outdated reviews}

Associations assessed in two or more reviews overlapped if they evaluated the same exposure and outcome. ${ }^{45}$ Incorporating results from reviews with overlapping associations could lead to the inclusion of primary studies more than once and result in biased findings and estimates. ${ }^{4647}$ Also, up to 50\% of published systematic reviews are out of date after 5.5 years. ${ }^{48}$ Reviews on cardiovascular disease topics have a shorter duration of currency (three years). ${ }^{48}$ We categorised overlapping systematic reviews as outdated (reviews older than five years or published before 2013) and contemporary (reviews published after 2013). Overlapping reviews that were out of date were excluded at the full text screening stage.

For contemporary reviews found to have overlapping associations (that is, investigating the same exposure and outcome), a graphical cross tabulation (citation matrix) of the overlapping systematic reviews (in columns) and the included primary studies (in rows) was generated. ${ }^{49}$ A citation matrix allows the degree of overlap to be quantified with a measure known as the corrected covered area (CCA). ${ }^{45} \mathrm{CCA}$, expressed as a percentage, is calculated as $(\mathrm{N}-\mathrm{r}) /(\mathrm{rc}-\mathrm{r})$, where $\mathrm{N}$ is the number of publications included in evidence synthesis (or the number of ticked boxes in the citation matrix), $r$ is the number of rows, and $\mathrm{c}$ is the number of columns. Overlap is categorised as very high (CCA $>15 \%$ ), high (CCA 11-15\%), moderate (CCA 6-10\%), or slight (CCA $0-5 \%) .{ }^{45} \mathrm{CCA}$ is a validated method of quantifying the degree of overlap between two or more reviews, and helps the decision process on how to deal with overlap when it is present. 
All non-overlapping systematic reviews that met the inclusion criteria (Cochrane and non-Cochrane) were included in the analysis. Appendix 3 shows the citation matrices for all studies with some degree of overlap. Overlap between reviews was managed as follows:

- Where overlap involved evidence synthesis from Cochrane and non-Cochrane reviews, the Cochrane review was selected in preference. ${ }^{50}$ A recent study examining the effect of different inclusion decisions on the comprehensiveness and complexity of overviews of reviews for healthcare interventions concluded that selecting the Cochrane review resulted in the least amount of data loss; also, Cochrane reviews were generally higher quality and tended to be more recent. ${ }^{51}$

- Where a high degree of overlap (CCA $\geq 11 \%$ ) between two or more non-Cochrane reviews was found, preference was given to the review that (in hierarchical order): had the highest rating, and at a minimum was rated as moderate quality, assessed with the AMSTAR 2 quality assessment tool; was most recent; supplied pooled effect estimates or had conducted a meta-analysis; and had the highest number of studies or participants. ${ }^{50}$

- Where a slight or moderate degree of overlap (CCA $\leq 10 \%$ ) was found, both reviews were retained, and the findings compared.

\section{Data synthesis}

Systematic reviews and meta-analyses that met the inclusion criteria formed the unit of analysis. Only data available from reviews were presented. Results from reviews were synthesised with a narrative synthesis, with tabular presentation of findings and forest plots for reviews that performed a meta-analysis. Summary tables describing review characteristics and findings were also presented.

\section{Update of eligible reviews}

The framework recommended by Garner et $\mathrm{al}^{52}$ was used to determine whether an update was necessary. An existing review qualified for an update if all of the following were met:

- The review was widely cited and achieved a minimum rating of moderate with the AMSTAR 2 quality appraisal tool. ${ }^{44}$ Reviews with low citations or a low quality rating were unsuitable for an update.

- With the key search terms from the search strategy of an existing review, a focused or abbreviated search of primary studies ${ }^{53}$ identified newly published studies that met the inclusion criteria of the review.

- The findings from newly published studies would change the conclusion or credibility of the review.

Appendix 4 describes the search strategy used to identify newly published studies. With findings from newly published studies, we evaluated the effect of updating existing reviews which met the above eligibility criteria. $^{52}$ As proposed by Chung et al, ${ }^{53}$ we relied on statistical methods (for reviews that conducted meta-analyses) and the informed opinion of subject experts (for reviews that did not perform metaanalyses).

In determining whether an original meta-analysis was out of date, newly published studies were sorted by sample size from the largest to the smallest. A fixed effect meta-analysis was then conducted by sequentially pooling (from the largest to the smallest) the effect estimate from newly published studies with the overall effect estimate of the original meta-analysis. The aim of this process was to identify whether a full update of the review was needed. An original metaanalysis was considered out of date if the addition of newly published studies resulted in a change of statistical significance or a change in the relative effect size by at least $50 \%$.

Based on the opinion of subject experts (TM and ST), the reviews that did not perform a meta-analysis were classified as definitely out of date, probably out of date, possibly out of date, and still valid. A review that was ranked definitely out of date or probably out of date was considered a high priority for update.

If an update was considered necessary, the original methods used in the conduct of the existing review were replicated. Appendix 5 summarises the evaluation process for considering reviews for update.54

\section{Patient and public involvement}

No patients were involved in setting the umbrella review question, in conducting the study, or in interpreting and writing up the results. The umbrella review was unfunded and was used to answer a specific question, where patient and public involvement will take place later in the work. We plan to engage with local policy makers (National Institute for Health and Care Excellence, Royal College of Obstetricians and Gynaecologists, Clinical commissioning groups) and local charities (British Heart Foundation), and to disseminate the research through social media (twitter), a press release from the Institute of Applied Health Research, University of Birmingham, and sharing of the research findings at relevant conferences.

\section{Results}

\section{Literature search}

The search retrieved 11345 articles. After removal of duplicates, and screening of titles and abstracts, 88 articles qualified for full text screening. Preliminary assessment of outdated overlapping reviews resulted in exclusion of 21 reviews. Applying the inclusionexclusion criteria identified 39 reviews for the umbrella review. Figure 1 summarises the study selection process. Appendix 6 provides the list of excluded studies, with reason for exclusion, after screening of the titles and abstracts.

\section{Methodological quality}

Thirty two reviews were rated as moderate in quality and seven reviews were rated as low in quality (appendix 7). All seven low quality reviews did not 


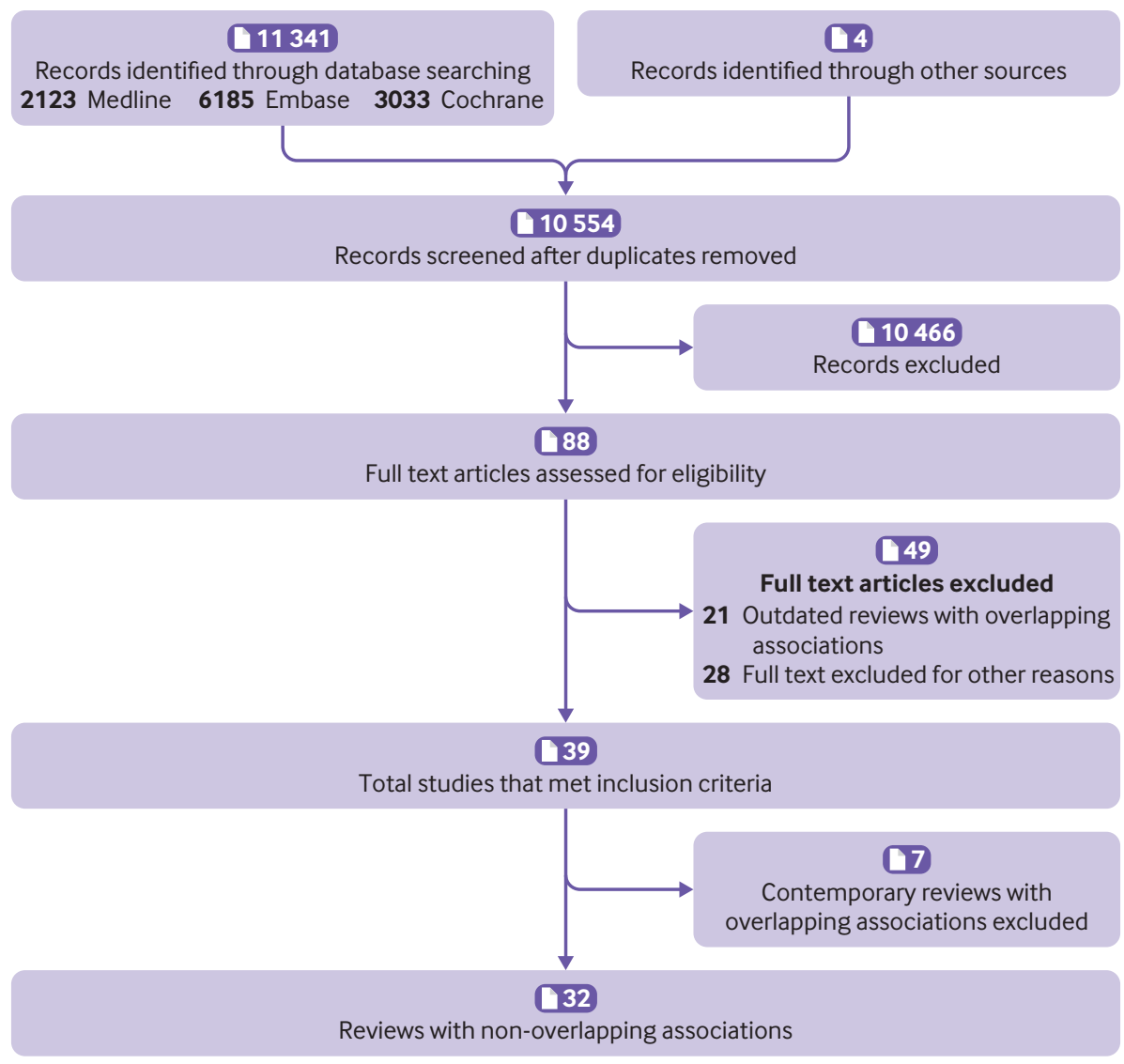

Fig 1 | Preferred Reporting Items for Systematic Reviews and Meta-Analyses (PRISMA) flow diagram

meet three of the seven domains considered critical: they had not stated that the review methods were established before conducting the review; they had not used a comprehensive search strategy; and they had not provided a list of excluded studies and the justification for their exclusion. ${ }^{44}$

\section{Overlapping and non-overlapping associations}

Twenty three reviews reported overlapping associations. ${ }^{55-77}$ Overlapping associations included: current use of combined oral contraceptives and risk of myocardial infarction, $\mathrm{n}=2^{5556}$; use of combined oral contraceptives and risk of ischaemic stroke, $n=3^{55-67}$; use of combined oral contraceptives and risk of haemorrhagic stroke, $n=2^{5671}$; use of progesterone only pill and risk of stroke, $n=2^{7273}$; use of combined oral contraceptives in migraine and risk of stroke, $n=2^{7475}$; early menarche and mortality from cardiovascular disease, $n=2^{7677}$; early menopause and risk of fatal cardiovascular disease, $n=3^{57-59}$; pre-eclampsia and risk of cardiovascular disease, $\mathrm{n}=2^{60}{ }^{61}$; gestational diabetes and risk of cardiovascular disease, $n=3^{626369}$; preterm birth and risk of cardiovascular disease, $\mathrm{n}=3^{6064}{ }^{65}$; and polycystic ovary syndrome and risk of cardiovascular disease, $n=3 .^{66} 6870$ Appendix 8 describes the general characteristics of the reviews with overlapping associations, including the decision to retain or exclude an association from the analysis.
Appendix 3 provides an example of the assessment of the degree of overlap with a citation matrix. Appendix 9 lists the thirty two reviews with non-overlapping associations that were included in the analysis and the seven contemporary reviews that were excluded because of overlap.

\section{Study characteristics of reviews with non- overlapping associations}

Factors related to fertility investigated in the included reviews were use of hormonal contraceptive agents $(n=9)$, fertility treatment $(n=1)$, early menarche $(n=2)$, polycystic ovary syndrome $(n=3)$, menopause $(n=4)$, parity $(n=2)$, and breastfeeding $(n=1)$. Adverse pregnancy outcomes included miscarriage $(n=1)$, preeclampsia $(n=2)$, gestational diabetes $(n=2)$, preterm births $(n=3)$, and multiple adverse pregnancy outcomes $(n=1)$. One study reviewed risk factors related to fertility and adverse pregnancy outcomes but was limited to heart failure as an outcome $(n=1)$. Of the 32 re-views included in the analyses, 24 conducted metaanalyses as the main form of evidence synthesis. The median length of follow-up was about 10 years for studies on risk factors related to fertility and 7.5 years for studies on adverse pregnancy outcomes. Supplementary table 1 summarises the general characteristics of the reviews and meta-analyses included in the umbrella review. 
Table 1 | Summary findings for each reproductive risk factor and effect sizes for cardiovascular outcomes

\begin{tabular}{l}
$\begin{array}{l}\text { Reproductive factors (related to } \\
\text { fertility) and fatality type } \\
\text { Early menarche }\end{array}$ \\
\hline Non-fatal \\
\hline Fatal \\
\hline Fatal and non-fatal \\
\hline Oral contraceptive pill use \\
\hline Non-fatal \\
\hline Fatal \\
\hline Fatal and non-fatal
\end{tabular}

\section{Current combined oral contraceptive use}

Non-fatal

Fatal

Fatal and non-fatal

\section{Progesterone only pill use}

Non-fatal

Fatal

Fatal and non-fatal

Combined oral contraceptives in obese women

Non-fatal
Composite cardiovascular disease

HR 1.15 (1.02 to 1.28$)$

RR 0.99 (0.98 to 1.01)

$-$

Effect size $(95 \% \mathrm{Cl})$

Ischaemic heart disease Stroke

Heart failure

$\begin{array}{ll}- & - \\ \text { RR } 0.97(0.95 \text { to } 0.99) & \text { RR } 0.98(0.95 \text { to } 1.01)\end{array}$

$-$

$\begin{array}{ll}- & \text { Ischaemic subtype, } \\ & \text { OR 2.47 (2.04 to 2.99) } \\ - & -\end{array}$

Haemorrhagic subtype,

OR 1.39 (1.05 to 1.83 )

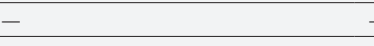

Myocardial infarction, Ischaemic subtype,

RR 1.6 (1.3 to 1.9$) \quad$ RR 1.7 (1.5 to 1.9$)$

Myocardial infarction,

RR 0.98 (0.66 to 1.47 )

RR 1.02 (0.72 to 1.44$)$

$-$

Myocardial infarction, OR $0.88 \quad$ OR 0.59 to 4.6

to 5.1

Fatal

Fatal and non-fatal

Oestrogen containing contraceptives in women with migraine

Non-fatal

Fatal

Fatal and non-fatal

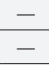

\section{Combined oral contraceptives in women with dyslipidaemia}

Non-fatal

$-$

$-$

\section{Fatal \\ Fatal and non-fatal \\ Combined oral contraceptives in women with hypertension \\ Non-fatal

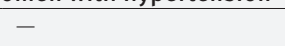

Fatal

Fatal and non-fatal

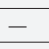

Combined non-oral hormonal contraceptives

Non-fatal

\begin{tabular}{l}
- \\
- \\
- \\
\hline
\end{tabular}

Fatal and non-fatal

Polycystic ovarian syndrome

Non-fatal

OR 1.30 (1.09 to 1.56$)$

OR 1.44 (1.13 to 1.84$)$

OR 1.36 (1.09 to 1.7$)$

OR 3.24 (0.53 to 19.94$)$

Fatal

Fatal and non-fatal

Fertility treatment

Non-fatal

Fatal

Fatal and non-fatal

Parity

Non-fatal

Fatal

Fatal and non-fatal

Breastfeeding

Non-fatal

Fatal

Fatal and non-fatal

Premature ovarian insufficiency

Non-fatal

Fatal

$-$

Myocardial infarction, OR 0.2 to $\quad$ OR 0.8 to 1.2

OR 1.6

Ischaemic subtype,

OR 2.08 to 16.9

Myocardial infarction, OR 25 (6 IRR 1.76 (1.51 to 2.06) to 109 )

Myocardial infarction, OR 6 to 68 Ischaemic subtype,

OR 3.1 to 14.5

\begin{tabular}{lll}
- & - & - \\
- & - & - \\
\hline & & - \\
Myocardial infarction, OR 0.2 to 1.6 & OR 0.8 to 1.2 & - \\
\hline
\end{tabular}

$-$

OR $1.44(1.13$ to 1.84$)$

$-\quad-\quad-$

$\begin{array}{ll}- & - \\ - & -\end{array}$

HR 0.91 (0.67 to 1.25$)$

HR 1.25 (0.96 to 1.63$)$

RR 0.79 (0.60 to 1.06$)$

RR 1.14 (1.09 to 1.18 )

HR 0.77 to 0.93

$-$

RR 1.24 (0.98 to 1.58$)$

HR 1.61 (1.22 to 2.12)

RR 1.48 (1.02 to 2.16)

HR 1.69 (1.29 to 2.21)

RR 1.00 (0.86 to 1.16)

HR 1.03 (0.88 to 1.99) 


\section{Table 1 | Continued}

Reproductive factors (related to fertility) and fatality type

Early menopause (natural and unnatural)

Non-fatal

Fatal

Fatal and non-fatal

Early natural menopause

Non-fatal

Fatal

Fatal and non-fatal

Menopausal symptoms

Non-fatal

Fatal

Fatal and non-fata

Miscarriage

Non-fatal

Fatal

Fatal and non-fata

Stillbirth

Non-fatal

Fatal

Fatal and non-fatal

Pre-eclampsia

Non-fatal

RR 1.19 (1.08 to 1.31)

Ischaemic heart disease

(l)

RR 1.50 (1.28 to 1.76$)$

RR 1.11 (1.03 to 1.20 )

RR 0.99 (0.92 to 1.07)

RR 1.09 (1.00 to 1.18)

RR 0.94 (0.86 to 1.03)

RR 1.01 (0.91 to 1.13)

RR 1.09 (1.00 to 1.18)

RR 1.18 (1.03 to 1.35$)$

RR 1.08 (0.89 to 1.32)

RR 1.29 (0.98 to 1.71)

OR 0.83 to 2.69

OR 1.49 (1.08 to 2.06)

OR 2.23 (1.90 to 2.62)

OR 2.24 (1.72 to 2.93)*;

OR 2.74 (2.48 to 3.04$) \dagger$

OR 1.73 (1.46 to 2.06)

Fatal

Fatal and non-fatal

Recurrent pre-eclampsia

Non-fatal

Fatal

Fatal and non-fatal

Gestational hypertension

Non-fatal

Fatal

Fatal and non-fatal

Gestational diabetes

Non-fatal

Fatal

Fatal and non-fatal

Placental abruption

Non-fatal

Fatal

Fatal and non-fatal

Preterm birth

Non-fatal

Fatal

Fatal and non-fatal

Recurrent preterm birth

Non-fatal

Fatal

Fatal and non-fatal

Low birth weight

Non-fatal

Fatal

Fatal and non-fatal

Small for gestational age

Non-fatal

Fatal

Fatal and non-fatal

-

$\begin{array}{llll}- & \text { RR 2.40 (2.15 to 2.68) } & \text { RR 1.69 (1.21 to 2.35) } & \text { RR 2.88 (2.23 to 3.72) } \\ - & - & - & - \\ - & - & - & -\end{array}$

RR 1.67 (1.28 to 2.19) $-$

-
-
RR 1.98 (1.57 to 2.50$)$
-
-
OR 1.82 (1.42 to 2.33$)$
OR 1.63 (1.39 to 1.93$)$
OR 1.93 (1.83 to 2.03$)$
HR 2.01 (1.52 to 2.65$)$

RR 1.83 (0.79 to 4.22)

-
-
-

(1.56 to 2.80$) \quad$ RR 1.25 (1.07 to 1.48$)$
RR 2.09 (1.56 to 2.80)

OR 1.73 (1.46 to 2.06$)$

RR 2.10 (1.25 to 3.51)

-
HR 2.1 (1.2 to 3.7 )

HR 1.4 (1.2 to 1.6$)$

HR 1.4 to 1.8

HR 1.8 (1.4 to 2.2)

OR 1.29 (0.91 to 1.83$)$

RR 1.49 (1.38 to 1.60)

RR 2.11 (1.87 to 2.36)

HR 1.38 (1.22 to 1.57)

RR 1.65 (1.51 to 1.79)

RR 1.30 (0.94 to 1.80)

HR 1.71 (1.53 to 1.91)

\author{
一
}

OR 2.95 (1.10 to 7.90$)$

RR 4.19 (2.09 to 8.38) 
A life course approach was adopted where exposures are presented from menarche to menopause for risk factors related to fertility, and from miscarriage to low birth weight for adverse pregnancy outcomes.

Factors related to fertility

Early age at menarche

Early age at menarche $(<12)$, compared with menarche after the age of 12 , was associated with a risk of morbidity from composite cardiovascular disease (table 1) ${ }^{78}$ No association between early age at menarche and mortality from cardiovascular disease was found. ${ }^{76}$ When examined by subtype of cardiovascular disease, an association between early age at menarche and risk of mortality from ischaemic heart disease was seen, but no association with mortality from stroke.

\section{Use of hormonal contraceptive agents}

Oral contraceptives and non-oral forms of combined hormonal contraceptives were associated with an increased risk of arteriothrombotic events (table 1). ${ }^{556779}$

\section{Use of oral contraceptives}

Current users of any oral contraceptive (combined oral contraceptives containing a combination of oestrogen and progesterone, or progesterone only pill) had an increased risk of stroke compared with noncurrent users. ${ }^{67} 71$ The increase in risk was greater for ischaemic stroke ${ }^{67}$ than haemorrhagic stroke. ${ }^{71}$ The risk of both ischaemic and haemorrhagic stroke was greatest in women on higher doses of oestrogen, who had hypertension, were smokers, or were aged over 35 (supplementary table 3).

Current users of combined oral contraceptives had a greater risk of developing myocardial infarction and stroke than non-current users of combined oral contraceptives. ${ }^{55}$ The same review ${ }^{55}$ showed that the risk was increased in women on higher doses of oestrogen but was not related to the dose, generation, or type of progesterone (supplementary table 3). In contrast, no association was seen between current use of the progesterone only pill and risk of myocardial infarction or stroke. ${ }^{72}$

\section{Use of non-oral contraceptive agents}

Comparing users of non-oral combined hormonal contraceptive agents with users of combined oral contraceptives, ${ }^{79}$ no association with the development of myocardial infarction (the results were not metaanalysed, but odds ratios from individual primary studies ranged from 0.2 to 1.6 ) or stroke (odds ratio 0.8 to 1.2) was seen but the review was rated as low quality (table 1 and supplementary table 4).

Use of hormonal contraceptive agents in women with coexisting medical illnesses

Use of hormonal contraceptive agents was associated with an additional risk of cardiovascular disease in women who had coexisting medical conditions. ${ }^{74} 8081$ The risk of stroke in women diagnosed with migraine was 2-16-fold greater for those taking combined hormonal contraceptive agents than those not taking combined hormonal contraceptives (table 1). ${ }^{74}$ Similarly, in women with dyslipidaemia, ${ }^{80}$ results derived from one primary study reported in the systematic review showed that users of combined hormonal contraceptive agents were at an increased risk of myocardial infarction ${ }^{82}$ and cerebrovascular accident compared with non-users (table 1). ${ }^{83}$ Use of combined oral contraceptives in women with hypertension women was associated with a much higher risk of myocardial infarction (odds ratio 6 to 68) and ischaemic stroke (odds ratio 3.1 to 14.5 ) than women with normal blood pressure taking non-combined oral contraceptives. ${ }^{84}$ But use of combined hormonal contraceptives in women with a high body mass index $\left(>27.3 \mathrm{~kg} / \mathrm{m}^{2}\right)$ was not found to be a multiplicative or additive risk factor for the development of myocardial infarction or stroke (table 1). ${ }^{81}$ Reviews assessing the association between the use of combined oral contraceptives in women with a high body mass index and the risk of myocardial infarction or stroke were rated as low quality (appendix 7).

\section{Polycystic ovary syndrome}

Women with polycystic ovary syndrome had a 1.3-fold greater risk of developing composite cardiovascular disease than women who did not have polycystic ovary syndrome (table 1). ${ }^{66}$ This increased risk was maintained when examining ischaemic heart disease $^{66}$ and stroke ${ }^{85}$ separately (supplementary table 3). Results from population based studies suggested that, compared with healthy controls, the risk of cardiovascular events was increased in young women in the reproductive age group with polycystic ovary syndrome (hazard ratio 1.43, 95\% confidence interval 1.27 to 1.61); no association was seen in postmenopausal women with polycystic ovary syndrome (supplementary table 3 ) $^{70}$ but this review was rated as low quality. Based on the results of one cross sectional study, ${ }^{86}$ no association was found between polycystic ovary syndrome and the risk of heart failure (table 1 and supplementary table 4). ${ }^{87}$

\section{Fertility treatment}

Women receiving fertility treatment (ovulation induction, in vitro fertilisation, and intrauterine insemination with drug treatment) had no greater risk of developing composite cardiovascular disease or stroke than infertile women not on fertility treatment. ${ }^{88}$

\section{Parity}

Mortality from composite cardiovascular disease was lower in ever parous women than nulliparous women (table 1). ${ }^{89}$ In a dose-response analysis, the association between ever parity and mortality from composite cardiovascular disease followed a J shaped curve with the risk lowest at a parity of four. For non-fatal events, ${ }^{90}$ however, the risk of composite cardiovascular disease was increased in ever parous women, with the risk increasing by $4 \%$ for each live birth. ${ }^{90}$ 


\section{Breastfeeding}

Evidence synthesised from four studies suggested that breastfeeding was associated with an overall reduction in maternal cardiovascular disease. ${ }^{91}$ Reviewers presented only a narrative review, without a metaanalysis (supplementary table 4). Compared with women who did not breastfeed, two US cohort studies found that morbidity from myocardial infarction ${ }^{92}$ and composite cardiovascular disease ${ }^{93}$ was lower in women with a lifetime length of lactation of more than 12 months. In a cohort of Chinese women, ${ }^{94}$ mortality from ischaemic heart disease but not stroke was lower in women who ever breastfed than in those who never breastfed. In a cohort of Norwegian women, ${ }^{95}$ women aged 65 or younger and who never breastfed were at a higher risk of mortality from stroke than women who ever breastfed.

\section{Menopause}

Overall, women who experienced menopause earlier than age 40 (premature ovarian insufficiency) had a 1.6-fold risk of developing composite cardiovascular disease compared with women without premature ovarian insufficiency. ${ }^{96}$ This association was related to the development of ischaemic heart disease ${ }^{96}$; no association was found with stroke. These findings were also reflected in the association with mortality risk from ischaemic heart disease, but not mortality from stroke or composite cardiovascular disease. ${ }^{59}$

Women who had experienced early (aged <45) menopause (natural and unnatural) had a 20\% higher risk of mortality after cardiovascular disease than women who had experienced menopause at age 45 or older. $^{57}$ Specifically, an increased risk of developing ischaemic heart disease (fatal and non-fatal outcomes) but not stroke was seen. ${ }^{57}$

Early (aged <45) natural menopause was not associated with a risk of mortality from composite cardiovascular disease or stroke, but was associated with a risk of mortality as a result of ischaemic heart disease. ${ }^{59}$ No association was seen between menopausal symptoms and risk of composite cardiovascular disease or stroke compared with women without menopausal symptoms ${ }^{97}$ but the risk was increased for ischaemic heart disease.

\section{Adverse pregnancy outcomes}

Pregnancy loss (miscarriage and stillbirth)

A history of miscarriage was not associated with an increased risk of composite cardiovascular disease (table 1).$^{60}$ In a review exploring individual cardiovascular diseases, miscarriage was linked to a higher risk of ischaemic heart disease but not of stroke. ${ }^{98}$ Women with a history of stillbirth had a greater risk of morbidity and mortality from composite cardiovascular disease than women with no history of stillbirth. ${ }^{60}$

Hypertensive disorders of pregnancy (pre-eclampsia and gestational hypertension)

Overall, women with a history of pre-eclampsia (both moderate and severe pre-eclampsia) were at an increased risk of mortality and morbidity from composite cardiovascular disease compared with those without a history of pre-eclampsia (table 1). ${ }^{60}$ For subtypes of cardiovascular disease, a history of pre-eclampsia was associated with a higher odds of experiencing heart failure, ${ }^{61}$ fatal ischaemic heart disease, ${ }^{61}$ and non-fatal stroke, ${ }^{60}$ but not fatal stroke. ${ }^{61}$

A small degree (CCA 5.6\%) of overlap was noted between two reviews ${ }^{6061}$ that investigated the association between pre-eclampsia and the risk of morbidity from ischaemic heart disease (appendix 3). One review ${ }^{61}$ searched for primary studies from 2005 only. The risk of non-fatal ischaemic heart disease in women with preeclampsia was 1.7-2-fold in the two reviews. ${ }^{6061}$

In comparison with an episode of pre-eclampsia followed by a healthy pregnancy, a history of recurrent pre-eclampsia was associated with an increased risk of composite cardiovascular disease, coronary heart disease, heart failure, and cerebrovascular accident. ${ }^{99}$ Gestational hypertension was linked to a greater risk of morbidity from composite cardiovascular disease but not stroke. ${ }^{60}$

\section{Gestational diabetes mellitus}

Women with a history of gestational diabetes had a greater risk of composite cardiovascular disease than those without gestational diabetes (table 1). ${ }^{62}$ The risk was highest in the first decade after pregnancy. ${ }^{62}$ When the analysis was limited to women who did not go on to develop diabetes mellitus after gestational diabetes, the risk was slightly less but remained statistically significant (supplementary table 3). ${ }^{62}$ The risk persisted when analysed by subtype of cardiovascular disease (coronary artery disease and stroke). ${ }^{63}$ Evidence of an association between gestational diabetes and heart failure $^{87}$ was inconclusive however (supplementary table 4). ${ }^{100101}$

\section{Placental abruption}

A history of placental abruption was associated with a higher odds of composite cardiovascular disease. ${ }^{60}$

\section{Preterm births}

Preterm delivery was associated with an increased risk of fatal and non-fatal composite cardiovascular disease. ${ }^{10260}$ For subtypes of cardiovascular disease, the risk was increased in non-fatal ischaemic heart disease, fatal ischaemic heart disease, and non-fatal stroke. ${ }^{64}$ The risk of composite cardiovascular disease was greater in women with multiple preterm births than in women with one preterm birth (table 1 and supplementary table 4). ${ }^{65}$

\section{Low birth weight and small for gestational age}

The risk of composite cardiovascular disease tended to be higher in women with babies of low birth weight than in women who delivered babies with an average birth weight (table 1). ${ }^{60}$ Small for gestational age was linked to an increased risk of morbidity and mortality from maternal cardiovascular disease (odds ratio 1.09 to 3.50) (supplementary table 4). ${ }^{60}$ 
Reviews eligible for update

We considered three reviews for update: assessing breastfeeding and the risk of cardiovascular disease, ${ }^{91}$ assessing miscarriage and the risk of stroke, ${ }^{98}$ and assessing gestational diabetes and the risk of stroke. ${ }^{63}$ Breastfeeding and the risk of cardiovascular disease was considered eligible for update because of conflicting evidence in the original review; findings for breastfeeding and the risk of cardiovascular disease risk are presented as a narrative summary in line with the method used in the original review. A meta-analysis was performed for miscarriage and the risk of stroke, and for gestational diabetes and the risk of stroke, to detect a signal indicating that the review would require a full update (as outlined above; eg, inclusion of a large new study that would result in a change to the conclusions of an existing review). After the metaanalysis, a full update was not considered necessary.

\section{Miscarriage}

A large (1031279 participants) Danish cohort study ${ }^{103}$ noted that women who had a miscarriage were at a higher risk of stroke (incidence rate ratio 1.16, 95\% confidence interval 1.07 to 1.25$)$. Incorporating the results in the meta-analysis on the risk of stroke with those of the existing systematic review ${ }^{98}$ did not alter the significance of the association between miscarriage and stroke. Figure 2 shows a forest plot of the results of the individual studies and the updated meta-analysis. ${ }^{103-106}$

\section{Gestational diabetes}

Two recent studies ${ }^{107} 108$ found no association between gestational diabetes and the risk of stroke (hazard ratio $1.10,95 \%$ confidence interval 0.75 to 1.61 ; incidence rate ratio $0.95,95 \%$ confidence interval 0.51 to 1.77 , respectively). When the results were incorporated into the meta-analysis on gestational diabetes and risk of stroke, ${ }^{63}$ the association between gestational diabetes and risk of stroke was maintained (risk ratio 1.21, 95\% confidence interval 1.05 to 1.40 ). Figure 3 shows a forest plot of the results of the individual studies and the updated meta-analysis. ${ }^{107-110}$

\section{Breastfeeding}

After the original review, ${ }^{91}$ six newly published observational studies ${ }^{111-116}$ (five cohort and one case- control study) examined the association between length of lactation and cardiovascular disease (table 2; supplementary table 5 provides more results for the primary studies in the original systematic review). The quality of the studies ranged from low to high (appendix 10). A longer length of breastfeeding was associated with a reduced risk of non-fatal composite cardiovascular disease compared with never breastfed in all three cohort studies. ${ }^{111} 114116$ Mortality from composite cardiovascular disease tended to be lower in women who breastfed for longer than in those who never breastfed, as assessed by two cohort studies. ${ }^{111} 116$ Two cohort studies showed that a longer length of breastfeeding was associated with reduced morbidity from coronary heart disease compared with never breastfed. ${ }^{115} 116$ In the casecontrol study, a U shaped association between length of breastfeeding and morbidity from coronary heart disease was seen, with the lowest risk in women who breastfed for 16-26 months over a total lifetime. ${ }^{112}$ Longer length of breastfeeding versus never breastfed was associated with reduced morbidity from stroke in two cohort studies. ${ }^{113116}$ In summary, newly published observational studies support an inverse association between length of lactation and morbidity or mortality from cardiovascular disease.

\section{Summary of results by cardiovascular outcome Composite cardiovascular disease}

Preterm birth, pre-eclampsia, and stillbirth were associated with a twofold increase in the risk of composite cardiovascular disease; premature ovarian insufficiency, placental abruption, gestational hypertension, and gestational diabetes mellitus were associated with a 1.5-1.9-fold increase in the risk; and polycystic ovary syndrome, early menopause, early menarche, and ever parity were associated with a less than 1.5-fold increase in risk. Breastfeeding for longer was associated with a reduced risk of cardiovascular disease. The forest plot (fig 4) shows the results for reviews that conducted a metaanalysis. ${ }^{5759606266767888-909697102}$

No association was found between cardiovascular disease outcomes and fertility treatment, current use of the progesterone only pill, or use of non-oral hormonal contraceptive agents.

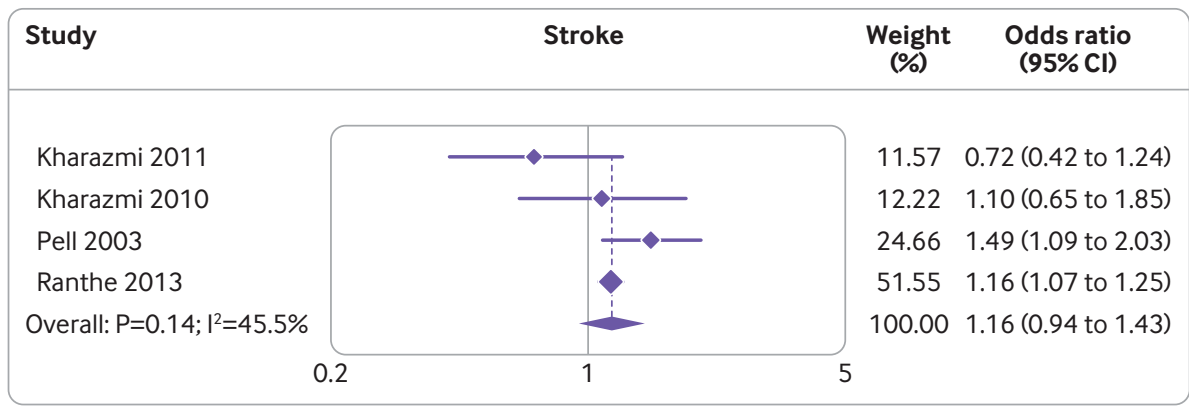

Fig 2 | Forest plot showing studies investigating the association between miscarriage and risk of stroke. Note, weights are from random effects analysis 


\begin{tabular}{|c|c|c|c|}
\hline Study & Stroke & $\begin{array}{l}\text { Weight } \\
\text { (\%) }\end{array}$ & $\begin{array}{l}\text { Relative risk } \\
\quad(95 \% \mathrm{Cl})\end{array}$ \\
\hline Carr 2006 & & 6.43 & $1.27(0.73$ to 2.21$)$ \\
\hline Goueslard 2016 & & 74.96 & 1.25 (1.07 to 1.48$)$ \\
\hline Daly 2018 & $一-$ & 5.09 & 0.95 (0.51 to 1.77$)$ \\
\hline Tobias 2017 & $-\gamma$ & 13.52 & $1.10(0.75$ to 1.61$)$ \\
\hline Overall: $P=0.80 ; 1^{2}=0 \%$ & $<$ & 100.00 & 1.21 (1.05 to 1.40$)$ \\
\hline 0.2 & 1 & & \\
\hline
\end{tabular}

Fig 3 | Forest plot showing studies investigating the association between gestational diabetes and risk of stroke. Note, weights are from random effects analysis

\section{Ischaemic heart disease}

A history of maternal delivery of preterm infants, gestational diabetes, pre-eclampsia, and recurrent pre-eclampsia were associated with a twofold or more increase in the risk of ischaemic heart disease; current use of combined oral contraceptives (oestrogen and progesterone), premature ovarian insufficiency, early menopause, and recurrent miscarriage were associated with a 1.5-1.9-fold increased risk; and polycystic ovary syndrome, menopausal symptoms, and miscarriage were associated with a less than 1.5 -fold increased risk (fig 5). $55576061636466727696-99102$

\section{Stroke}

Current use of any oral contraceptives (combined oral contraceptives and progesterone only pill), recurrent pre-eclampsia, and pre-eclampsia were associated with a twofold or more increased risk of stroke; maternal delivery of preterm infants, gestational diabetes, and current use of combined oral contraceptives were associated with a 1.5-1.9-fold increase in risk; and polycystic ovary syndrome was associated with a less than 1.5 -fold increase in risk (fig 6). $5557596061636467717276858896-99102$

\section{Heart failure}

Pre-eclampsia was associated with a fourfold increase in the risk of heart failure (fig 7). ${ }^{6199}$

\section{Discussion}

This detailed umbrella review synthesised existing systematic reviews and meta-analyses into one user friendly document. The review has updated a previous systematic review on the association between breastfeeding and maternal cardiovascular outcomes, and identified gaps and proposed recommendations for research and practice, particularly with respect to relevant UK guidelines (National Institute for Health and Care Excellence, Royal College of Obstetricians and Gynaecologists, and Faculty of Sexual and Reproductive Healthcare).

\section{Main findings}

Evidence from the umbrella review suggests that current use of combined oral contraceptives, use of combined hormonal contraceptive agents in women with dyslipidaemia, use of combined hormonal contraceptive agents in women with hypertension, use of oestrogen containing pills in women with migraine, polycystic ovary syndrome, premature ovarian insufficiency, early menarche, early menopause, menopausal symptoms, parity, pre-eclampsia, recurrent pre-eclampsia, preterm births, gestational diabetes, gestational hypertension, miscarriages, stillbirths, placental abruption, and small for gestational age are associated with an increased risk of cardiovascular disease outcomes. The review on length of lactation and the recently published studies suggest that breastfeeding for longer reduces the risk of cardiovascular disease. Length of lactation might be a proxy for general health state but never breastfed was associated with vascular characteristics (larger arterial lumen and adventitial diameters) linked to a higher risk of cardiovascular disease independent of sociodemographic characteristics, health related behaviour, family history, and body mass index. ${ }^{117} 118$ The evidence was inconclusive on the association between use of combined hormonal contraceptive agents in women with a high body mass index (>27.3) and the risk of cardiovascular disease outcomes. No association was found between current use of progesterone only contraceptives, use of non-oral combined hormonal contraceptive agents, or fertility treatment and the risk of cardiovascular disease outcomes. Reviews on endometriosis, pelvic inflammatory disease, and anaemia during pregnancy were absent.

\section{Strengths and limitations}

The umbrella review has many strengths. A comprehensive search strategy was used to identify relevant reviews. The methodological quality of the studies included in the review was assessed with the AMSTAR 2 tool. Where eligible, reviews were updated to ensure the evidence was current. Evaluation of CCA and reporting of the highest quality and most current review from reviews with overlapping associations were used to eliminate double counting. Methodological rigour in the conduct of the review was achieved by following PRISMA guidelines.

Several limitations arose. Lack of data, including missing metadata (number of participants and events), hindered the reporting of some elements of 
Table 2 | Summary of primary observational studies (newly published) investigating the association between breastfeeding and risk of maternal cardiovascular disease

\begin{tabular}{|c|c|c|c|c|}
\hline Study, setting, and objective & $\begin{array}{l}\text { Study design and par- } \\
\text { ticipants }\end{array}$ & Exposure and comparator & Outcome & $\begin{array}{l}\text { Length of breastfeeding } \\
\text { (effect size }(95 \% \mathrm{CI}))\end{array}$ \\
\hline \multicolumn{5}{|c|}{ Nguyen $2019,{ }^{111}$ New South Wales, Australia } \\
\hline \multirow{8}{*}{$\begin{array}{l}\text { To examine the association between } \\
\text { breastfeeding and hospital } \\
\text { admission for cardiovascular } \\
\text { disease and death }\end{array}$} & \multirow{8}{*}{$\begin{array}{l}\text { Cohort of } 100864 \text { middle } \\
\text { aged and parous women }\end{array}$} & \multirow{8}{*}{$\begin{array}{l}\text { Self-reported breastfeeding, } \\
\text { never } v \text { ever and average } \\
\text { breastfeeding duration per child }\end{array}$} & \multirow{4}{*}{$\begin{array}{l}\text { Non-fatal cardiovascular } \\
\text { disease }\end{array}$} & Never breastfed (reference) \\
\hline & & & & 0-6 months, HR 0.86 (0.78 to 0.96) \\
\hline & & & & 6-12 months, HR 0.85 (0.75 to 0.97$)$ \\
\hline & & & & >12 months, HR 0.89 (0.71 to 1.12) \\
\hline & & & \multirow{4}{*}{$\begin{array}{l}\text { Fatal cardiovascular } \\
\text { disease }\end{array}$} & Never breastfed (reference) \\
\hline & & & & 0.6 months, HR 0.69 (0.51 to 0.94) \\
\hline & & & & 6-12 months, HR 0.59 (0.41 to 0.84) \\
\hline & & & & >12 months, HR 0.67 (0.28 to 1.57) \\
\hline
\end{tabular}

Rajaei $2019,{ }^{112}$ Stanford, USA

To evaluate the association between Hospital case-control lactation duration and risk of study of 643 nulliparous developing non-fatal coronary artery and multiparous women disease
Exposure category 1: single Non-fatal coronary artery $\quad$ Live delivery but never breastfed (reference) longest duration of breastfeeding disease of all live births the umbrella review. Certain reproductive factors, including endometriosis, pelvic inflammatory disease, first trimester bleeding without miscarriage, and anaemia in pregnancy, have been linked to an increased risk of future cardiovascular disease events. ${ }^{19} 20$ 119-121 Systematic reviews on these exposures could not be identified, however, and therefore these factors were not incorporated in our analyses. Conversely, for some reproductive factors, including age at first birth, ${ }^{122}$ evidence from a systematic review was identified, but because of inherent methodological shortcomings, ${ }^{40}$ the review did not meet our inclusion criteria.

With the AMSTAR 2 quality appraisal instrument, some reviews were rated as low quality, and none of the reviews was rated as high in quality. Insufficient reporting by review authors rather than shortcomings of the review methods could have inadvertently led to a downgrading of the quality of the review. Also, the reviews included were necessarily based on observational evidence; consequently, as noted by Grandi et al, ${ }^{60}$ the possibility of confounding remains because of unknown confounders or lack of adjustment for known confounders. The review by Grandi et al noted that a large number of studies failed to adjust for all key risk factors and therefore the results should be interpreted with caution. Misclassification of exposure or outcome status in the studies included in the review is also possible.

\section{Methodological issues}

The evidence in the umbrella review was from observational study designs which are prone to 


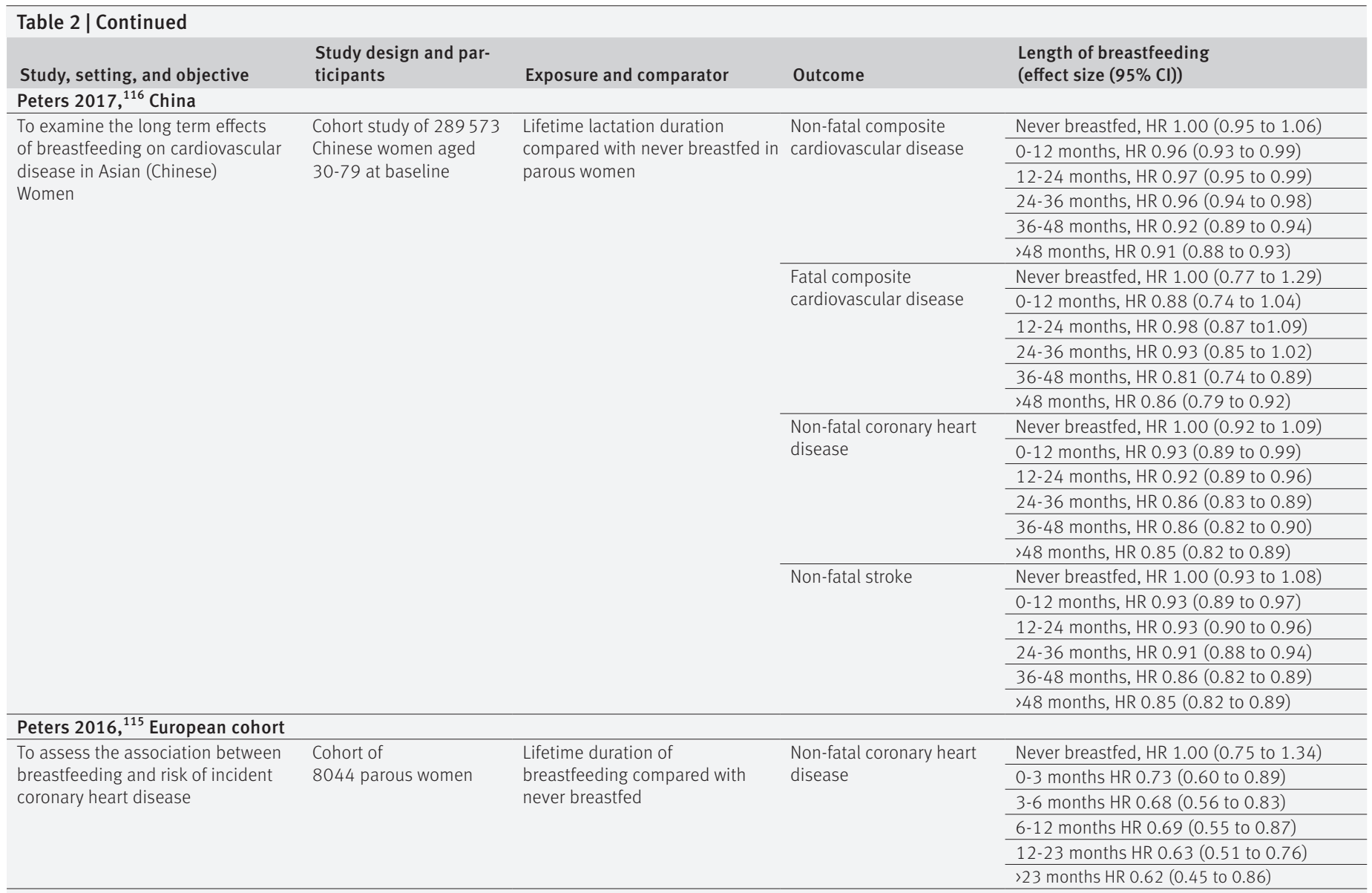

residual confounding. In some instances, evidence was derived from one study or pooled studies which recorded a small number of events, leading to imprecise results. Also, some of the evidence was derived from cross sectional studies which are poor in determining temporal associations.

Several associations between reproductive factors and cardiovascular disease had a high degree of between study heterogeneity. Several reviews could not evaluate the presence of publication bias because of the small number of studies in the meta-analyses. ${ }^{123}$ Information from some of the primary studies was self-reported, which might lead to potential misclassification and recall bias.

\section{Relation to evidence based guidelines and other reviews \\ Factors related to fertility}

Evidence presented in this review on combined hormonal contraceptive agents and combined oral contraceptives are in keeping with findings on the adverse effects of the use of hormonal contraceptive agents reported in current evidence based guidelines. ${ }^{124}$ Also, the findings of this review agree with the consensus statement from the European Headache Federation, which reported that the risk of stroke was greater in women with migraine. ${ }^{125}$ But caution should be exercised in the interpretation of findings on the use of combined oral contraceptives and the arteriothrombotic risk. Firstly, the between study heterogeneity was high. Secondly, publication bias was not always assessed so its presence cannot be ruled out. ${ }^{55}$ Finally, results on current use of combined oral contraceptives in women with dyslipidaemia and current use of combined oral contraceptives in women with obesity were imprecise because they included a small number of studies. Although the absolute risk of cardiovascular disease associated with the use of combined oral contraceptives is low (about 10 per 100000 person years for myocardial infarction and 21 per 100000 person years for stroke), ${ }^{21}$ a large proportion of women (up to $18 \%$ in Europe and North America in 2019) in the reproductive age group use contraceptive pills ${ }^{126}$; hence clinicians should discuss this risk with patients and ensure that women are aware of the association between the use of combined oral contraceptives and the increased risk of cardiovascular disease.

The evidence reported supports the results from an overview of reviews that investigated the association between polycystic ovary syndrome and system wide complications, including cardiovascular disease. ${ }^{68}$ The overview summarised evidence from two systematic reviews. ${ }^{66127}$ Our review synthesised evidence from another three reviews, including one evaluating the risk of heart failure, ${ }^{70} 8587$ but no evidence of an 
increased risk of heart failure in women with polycystic ovary syndrome was found. Results on the risk of heart failure were based on one cross sectional study that reported imprecise results. Moreover, cross sectional studies cannot be used to infer causality.

Guidelines on the prevention of cardiovascular disease recognise perimenopause and menopause as periods when women are vulnerable to cardiovascular disease. ${ }^{128} 129$ In line with findings in the evidence based guideline on the management of women with premature ovarian insufficiency, ${ }^{130}$ the evidence we evaluated reported an increased risk of ischaemic heart disease and cardiovascular disease associated with premature menopause. Also, early menopause and menopausal symptoms were associated with an increased risk of ischaemic heart disease.

\section{Adverse pregnancy outcomes}

Findings from our review are consistent with European and American evidence based guidelines on prevention of cardiovascular disease that highlighted pre-eclampsia, gestational diabetes, and preterm birth as adverse pregnancy outcomes that potentially increase the risk of cardiovascular disease. ${ }^{131-134}$ Also, this review reports evidence of an increased risk of cardiovascular disease outcomes in women with stillbirths, small for gestational age offspring, and placental abruption. We reported that the increased risk of composite cardiovascular disease but not stroke was statistically significant (odds ratio 1.67 , $95 \%$ confidence interval 1.28 to 2.19 ) in women with gestational hypertension. These findings are in keeping with a meta-analysis, ${ }^{135}$ published beyond the time line of this review, which reported that women with gestational hypertension had an increased risk of composite cardiovascular disease (relative risk 1.73, $95 \%$ confidence interval 1.43 to 2.09 ), stroke (1.66, 0.99 to 2.79$)$, coronary heart disease $(1.56,1.35$ to 1.81), and heart failure (1.70, 1.43 to 2.02$)$.

In an umbrella review, ${ }^{136}$ an inverse association between birth weight and future maternal cardiovascular disease was reported (hazard ratio 0.75, $95 \%$ confidence interval 0.67 to 0.84 , for every one standard deviation increase from the mean weight). An analysis reported in another review, ${ }^{60}$ which excluded studies with self-reported low birth weight and those that reported less severe forms of cardiovascular disease, revealed a statistically significant association (odds ratio 1.46, 95\% confidence interval 1.11 to 1.91) between low birth weight and cardiovascular disease, ${ }^{60}$ in agreement with the findings of the umbrella review ${ }^{136}$ (supplementary table 3).

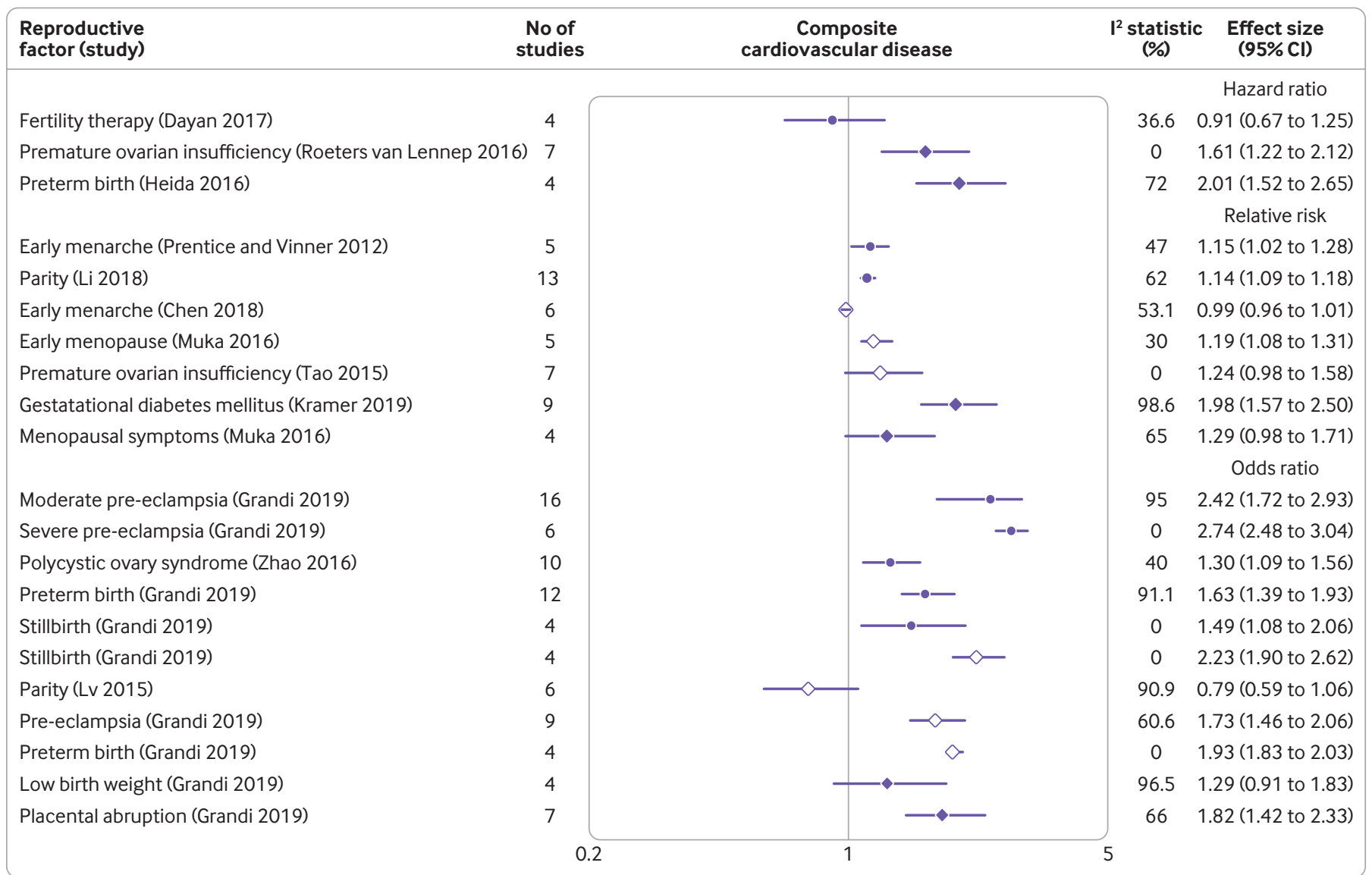

Fig 4 | Forest plot showing results of meta-analyses from reviews that investigated the association between various reproductive factors and risk of composite cardiovascular disease. Circles indicate non-fatal outcomes, open diamonds fatal outcomes, and filled diamonds combined fatal and nonfatal outcomes 


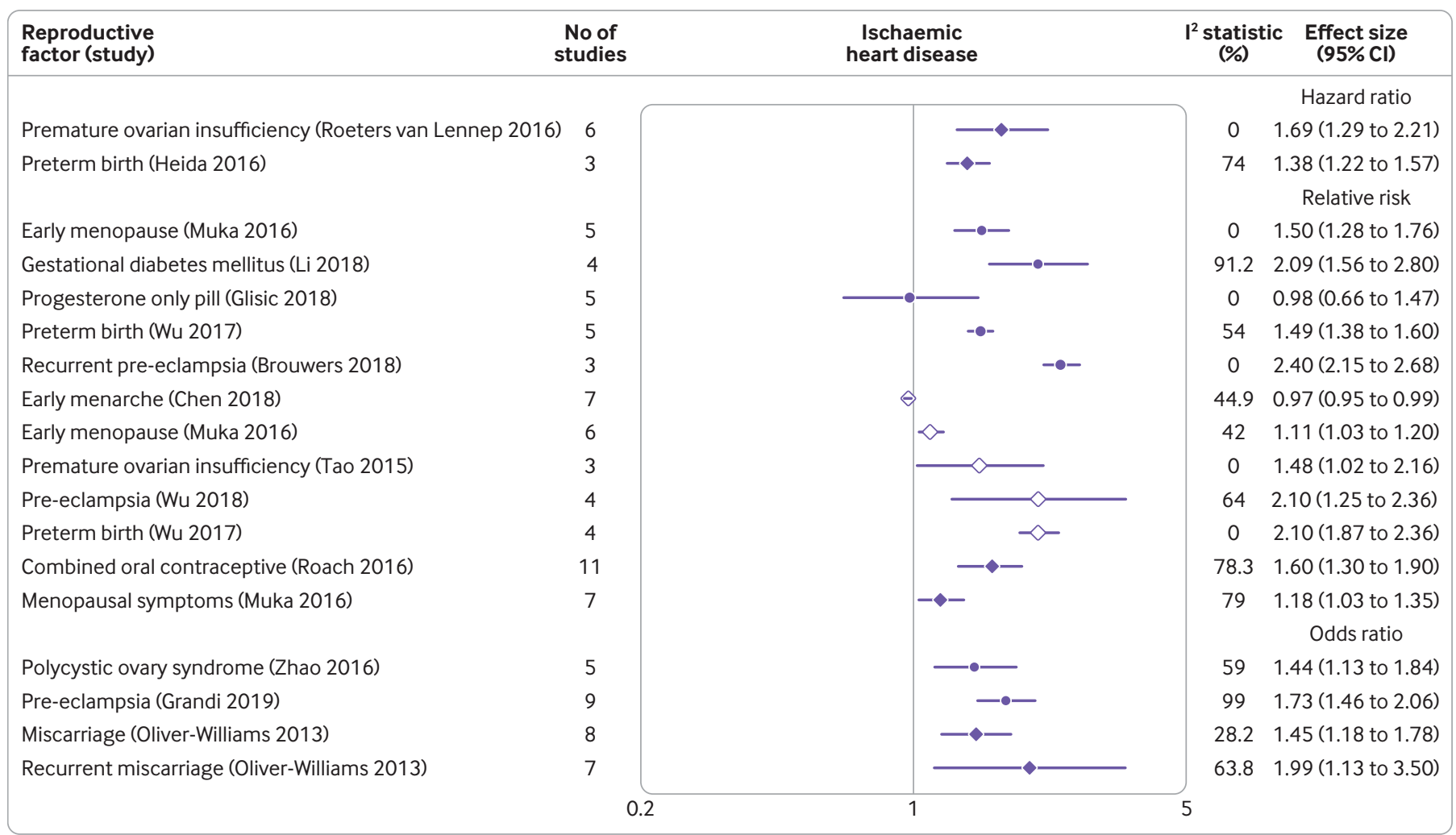

Fig 5 | Forest plot showing results of meta-analyses from reviews that investigated the association between various reproductive factors and risk of ischaemic heart disease. Circles indicate non-fatal outcomes, open diamonds fatal outcomes, and filled diamonds combined fatal and non-fatal outcomes

Biological plausibility

Multifactorial mechanisms might explain the increased risk of cardiovascular disease associated with various reproductive factors. Families of women with a history of reproductive complications were also at an increased risk of cardiovascular disease and so genetic predispositions could have a role. ${ }^{137} 138$ Use of hormonal contraceptive agents might result in a homeostasis imbalance by favouring procoagulant factors and decreasing anticoagulant factors. ${ }^{139}$ Metabolic derangements linked to the risk of cardiovascular disease, including weight gain, decreased insulin sensitivity, dyslipidaemia, and hypertension, are prevalent in women with risk factors for cardiovascular disease specific to women (eg, factors related to fertility and adverse pregnancy outcomes). ${ }^{140-145}$ On the other hand, in young women aged 50 or younger, prolonged lactation was inversely linked to risk factors for cardiovascular disease, including total cholesterol, body mass index, waist circumference, and hypertension, which might be linked to the reduced risk of cardiovascular disease noted in these women. ${ }^{146}$

Endothelial dysfunction, which has been found in women with premature menopause and in those with adverse pregnancy outcomes, might trigger pregnancy complications and remain beyond these complications to predispose women to future cardiovascular disease. ${ }^{13} 147$ Parity of four or more is associated with an increased risk of cardiovascular disease through an accelerated atherosclerotic process in both younger and older women. ${ }^{148}$

\section{Implications for practice and public health}

The implications for practice include early or routine screening and assessment for cardiovascular disease and risk factors; routine postpartum followup and monitoring, involving multidisciplinary healthcare professionals (eg, general practitioners, gynaecologists, cardiologists); improving education and awareness for patients and clinicians; and use of timely treatment. ${ }^{149} \mathrm{~A}$ high proportion of women will encounter a clinician for the first time when planning for a family and during pregnancy. Obstetricians and gynaecologists should, therefore, be involved in the referral and follow-up of patients potentially at risk. A multidisciplinary approach between general practitioners, specialist physicians, and obstetricians and gynaecologists is recommended. ${ }^{150}$ Likewise, educating practitioners in the primary care setting on the importance of taking a thorough reproductive history and recording factors related to fertility or adverse pregnancy outcomes is essential. Information from this history could prove crucial in identifying patients at high risk for prevention of cardiovascular disease and follow-up. Our previous study found insufficient reporting of gestational diabetes and screening for cardiovascular risk factors in these 


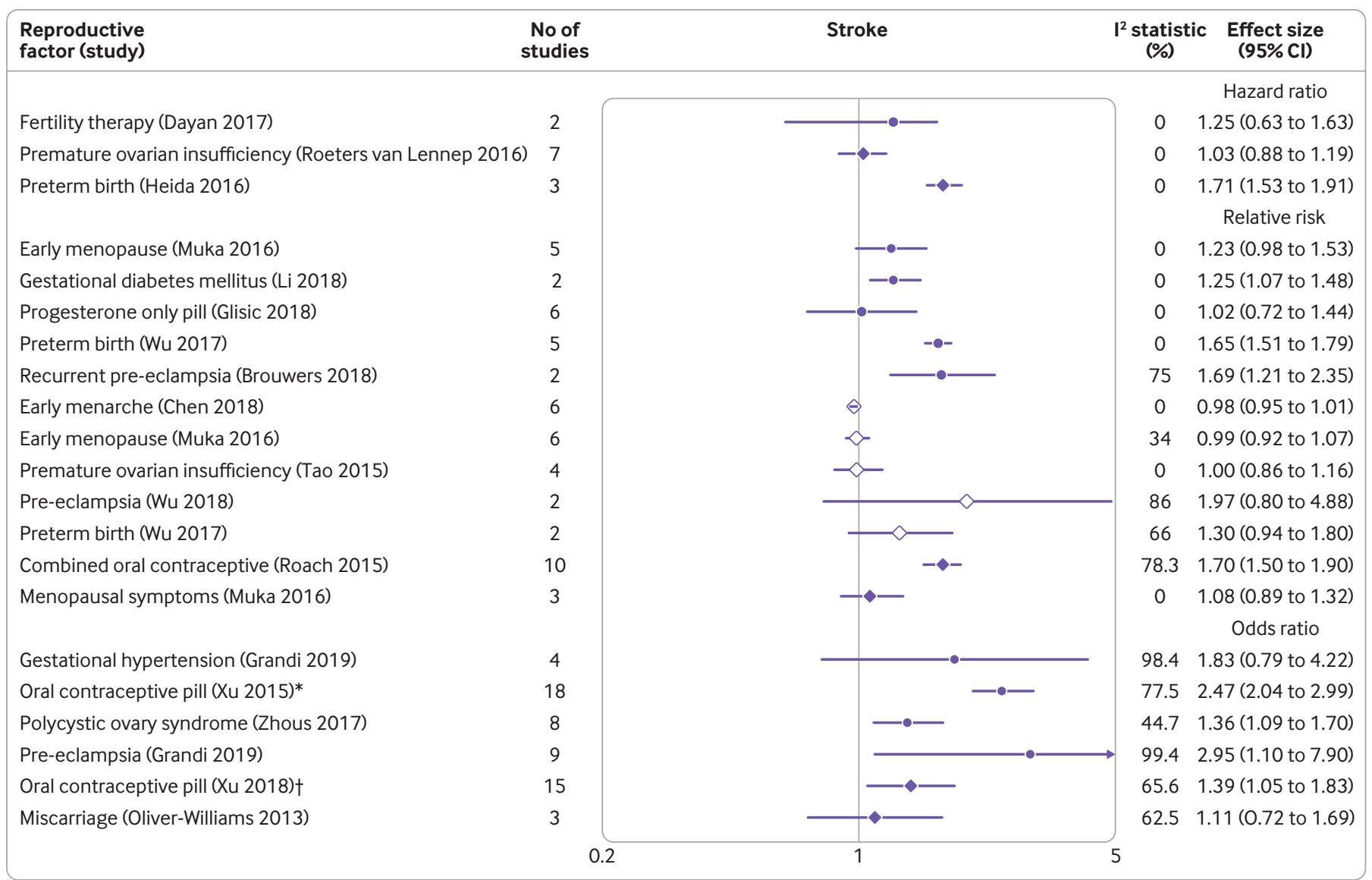

Fig 6 | Forest plot showing results of meta-analyses from reviews that investigated the association between various reproductive factors and risk of stroke. Circles indicate non-fatal outcomes, open diamonds fatal outcomes, and filled diamonds combined fatal and non-fatal outcomes. *Ischaemic stroke. HHaemorrhagic stroke

women. ${ }^{108}$ Adverse pregnancy outcomes should be communicated to primary care and reported in primary care records so these factors can be used for future risk stratification, and patients recalled for risk assessment of cardiovascular disease.

Hospital episodes related to cardiovascular disease occurred in 381458 women in the financial year $2017-18,{ }^{151}$ indicating an incidence of about 113.4 cardiovascular disease episodes per 10000 women annually. A study focusing only on coronary heart disease suggested that $15 \%$ of coronary heart disease in women younger than 65 cannot be explained by existing risk factors. ${ }^{34}$ Therefore, we believe that if we were to look at care pathways of women with reproductive risk factors, a large proportion of cardiovascular disease would be hypothetically preventable. But quantifying how much is preventable is difficult given that many of these risk factors might cluster together; also, how many of the risk factors are modifiable, and whether, if modified, a reduction in cardiovascular events will be seen is unclear. Nevertheless, screening for risk factors in these women and management of these reproductive risk factors might not only reduce the risk of cardiovascular disease as a result of the reproductive risk factors themselves, but also reduce the risk caused by traditional risk factors for cardiovascular disease (eg, improving care pathways for women with gestational diabetes will enable early identification of diabetes mellitus and also other risk factors, thereby reducing cardiovascular events).

\begin{tabular}{|c|c|c|c|c|c|}
\hline $\begin{array}{l}\text { Reproductive } \\
\text { factor (study) }\end{array}$ & $\begin{array}{l}\text { No of } \\
\text { studies }\end{array}$ & $\begin{array}{l}\text { Heart } \\
\text { failure }\end{array}$ & & $\begin{array}{c}I^{2} \text { statistic } \\
(\%)\end{array}$ & $\begin{array}{c}\text { Relative risk } \\
(95 \% \mathrm{Cl})\end{array}$ \\
\hline Pre-eclampsia (Wu 2018) & 4 & & $\longrightarrow$ & 71 & 4.19 (2.09 to 8.38$)$ \\
\hline \multirow[t]{2}{*}{ Recurrent pre-eclampsia (Brouwers 2018) } & 2 & & $-\bullet-$ & 27 & 2.88 (2.23 to 3.72$)$ \\
\hline & 0.2 & 1 & & 5 & \\
\hline
\end{tabular}

Fig 7 | Forest plot showing results of meta-analyses from reviews that investigated the association between various reproductive factors and risk of heart failure. Circles indicate non-fatal outcomes 
Implications for future research

Several reproductive factors have been linked to an increased risk of ischaemic heart disease, stroke, and overall cardiovascular disease. These reproductive factors might be linked to the risk of peripheral arterial disease and heart failure, and therefore longitudinal studies are needed in this area.

Evidence from the review has suggested that women with adverse pregnancy outcomes are at risk of future cardiovascular disease outcomes. Current guidelines on prescription of contraceptives recommend a careful assessment of the eligibility for combined oral contraceptives in women with migraine, diabetes, and other existing conditions associated with a high risk of cardiovascular disease. ${ }^{152}$ These guidelines do not include recommendations on the safety profile of the use of combined oral contraceptives in women with adverse pregnancy outcomes and other complications related to fertility. Also, the interaction between adverse pregnancy outcomes, factors related to fertility, and other conditions predominant in women (migraine, autoimmune diseases) that predispose to cardiovascular disease needs to be investigated.

That pregnancy complications act as a stress test that unmasks women who are at an increased risk of cardiovascular disease has been postulated. ${ }^{153}$ Whether adverse pregnancy outcomes and reproductive factors related to fertility directly cause or act as stressors that reveal those who are already susceptible to cardiovascular disease needs to be determined. This information will help in starting preventive strategies early. Moreover, the mechanistic pathways between these reproductive factors and risk of cardiovascular disease need to be determined. ${ }^{154}$

Prediction models for traditional risk factors for cardiovascular disease could underestimate the true risk of cardiovascular disease in young women because they do not account for risk factors specific to women. ${ }^{155} \mathrm{~A}$ recent systematic review on risk prediction models for cardiovascular disease in women noted that only $1.1 \%$ of the 260 articles included in the review investigated the added value of incorporating risk factors specific to women in risk prediction models. ${ }^{156}$ Even in studies that evaluated the use of predictors specific to women, however, none included predictors such as hypertensive disorders of pregnancy, gestational diabetes, polycystic ovary syndrome, and premature ovarian insufficiency. The benefit of adding reproductive factors to risk prediction models for cardiovascular disease needs to be extensively evaluated.

Should the reproductive profile prove useful in the early prediction of cardiovascular disease, it would be equally essential to determine the effectiveness of intensive screening and monitoring. ${ }^{157}$ Conventional risk factors for cardiovascular disease, including hypertension and body mass index, have been associated with an excess risk of cardiovascular disease in women with hypertensive disorders of pregnancy. $^{33}$ Determining whether women with reproductive profiles that place them at an increased risk of cardiovascular disease might be candidates for lifestyle changes, including statin treatment, is essential. Also, interventions to promote a healthy lifestyle, epidemiological data and trends, and randomised controlled trials that assess early intervention in women with risk factors should be evaluated. ${ }^{149}$

\section{Conclusion}

In summary, the evidence reported in this umbrella review suggests that, from menarche to menopause, the reproductive profile of women is associated with their future risk of cardiovascular disease. Large prospective studies are needed to confirm the association between current use of combined oral contraceptives in patients with obesity and the risk of cardiovascular disease. Similarly, prospective studies with a longer duration of follow-up are needed to investigate the association between reproductive factors and the risk of heart failure. A large proportion of unexplained risk of cardiovascular disease in women might be attributable to reproductive risk factors but the exact magnitude of the effect is unclear. Identification of reproductive risk factors at an early stage in the life course of women might facilitate the initiation of strategies to modify potential risks. Future research on the benefit of adding risk factors specific to women to prediction models for cardiovascular disease and on the mechanistic pathways that underlie the association between reproductive factors and cardiovascular disease is required. Policy makers should consider incorporating reproductive risk factors as part of the risk assessment for cardiovascular disease in clinical guidelines.

Contributors: $\mathrm{KN}$ and $\mathrm{KO}$ developed the review question. $\mathrm{KO}$ was the first reviewer, JSC was the second reviewer, and NJA and KN acted as third reviewers where required. NJA, KN, and GNT supervised the study and analysis. KO, NJA, and KN drafted the manuscript. GNT, KN, and NJA are joint senior authors. All authors reviewed and revised the manuscript. KO acts as guarantor. The corresponding author attests that all listed authors meet authorship criteria and that no others meeting the criteria have been omitted.

Funding: None.

Competing interests: All authors have completed the ICMIE uniform disclosure form at http://www.icmje.org/coi_disclosure.pdf and declare: no support from any organisation for the submitted work; no financial relationships with any organisations that might have an interest in the submitted work in the previous three years; no other relationships or activities that could appear to have influenced the submitted work; KN reports funding from AstraZeneca and fees from Sanofi, MSD, and Boehringer Ingelheim outside the submitted work. Ethical approval: Not applicable.

Data sharing: No additional data available.

The lead author (the manuscript's guarantor) affirms that this manuscript is an honest, accurate, and transparent account of the study being reported; that no important aspects of the study have been omitted; and that any discrepancies from the study as planned (and, if relevant, registered) have been explained.

Dissemination to participants and related patient and public communities: Dissemination to participants is not possible as this is a review of existing evidence. Patients and the public will not be involved in dissemination of the findings.

Provenance and peer review: Not commissioned; externally peer reviewed.

This is an Open Access article distributed in accordance with the Creative Commons Attribution Non Commercial (CC BY-NC 4.0) license, which permits others to distribute, remix, adapt, build upon this work 
non-commercially, and license their derivative works on different terms, provided the original work is properly cited and the use is noncommercial. See: http://creativecommons.org/licenses/by-nc/4.0/.

1 Cardiovascular diseases. https://www.who.int/health-topics/ cardiovascular-diseases/

2 Wilmot KA, O'Flaherty M, Capewell S, Ford ES, Vaccarino V. Coronary heart disease mortality declines in the United States from 1979 through 2011: evidence for stagnation in young adults, especially women. Circulation 2015;132:997-1002. doi:10.1161/ CIRCULATIONAHA.115.015293

3 Ford ES, Capewell S. Coronary heart disease mortality among young adults in the U.S. from 1980 through 2002: concealed leveling of mortality rates. J Am Coll Cardiol 2007;50:2128-32. doi:10.1016/j. jacc.2007.05.056

4 Nedkoff LJ, Briffa TG, Preen DB, et al. Age- and sex-specific trends in the incidence of hospitalized acute coronary syndromes in Western Australia. Circ Cardiovasc Qual Outcomes 2011;4:557-64. doi:10.1161/CIRCOUTCOMES.110.960005

5 Izadnegahdar M, Singer J, Lee MK, et al. Do younger women fare worse? Sex differences in acute myocardial infarction hospitalization and early mortality rates over ten years. I Womens Health (Larchmt) 2014;23:10-7. doi:10.1089/jwh.2013.4507

6 Arora S, Stouffer GA, Kucharska-Newton AM, et al. Twenty year trends and sex differences in young adults hospitalized with acute myocardial infarction. Circulation 2019;139:1047-56. doi:10.1161/ CIRCULATIONAHA.118.037137

7 Gupta A, Wang Y, Spertus JA, et al. Trends in acute myocardial infarction in young patients and differences by sex and race, 2001 to 2010. J Am Coll Cardiol 2014;64:337-45. doi:10.1016/j. jacc.2014.04.054

8 Ramirez L, Kim-Tenser MA, Sanossian N, et al. Trends in acute ischemic stroke hospitalizations in the United States. J Am Heart Assoc 2016;5:e003233. doi:10.1161/JAHA.116.003233

9 Gabet A, Danchin N, Juillière Y, Olié V. Acute coronary syndrome in women: rising hospitalizations in middle-aged French women, 2004-14. Eur Heart J 2017;38:1060-5. doi:10.1093/eurheartj/ ehx097

10 Huxley R, Barzi F, Woodward M. Excess risk of fatal coronary heart disease associated with diabetes in men and women: meta-analysis of 37 prospective cohort studies. BMJ 2006;332:73-8. doi:10.1136/ bmj.38678.389583.7C

11 Prescott E, Hippe M, Schnohr P, Hein HO, Vestbo J. Smoking and risk of myocardial infarction in women and men: longitudinal population study. BMJ 1998;316:1043-7. doi:10.1136/bmj.316.7137.1043

12 Humphries KH, Izadnegahdar M, Sedlak T, et al. Sex differences in cardiovascular disease - Impact on care and outcomes. Front Neuroendocrinol 2017;46:46-70. doi:10.1016/j.yfrne.2017.04.001

13 Germain AM, Romanik MC, Guerra I, et al. Endothelial dysfunction: a link among preeclampsia, recurrent pregnancy loss, and future cardiovascular events?Hypertension 2007;49:90-5 doi:10.1161/01.HYP.0000251522.18094.d4

14 Hermes W, Ket JCF, van Pampus MG, et al. Biochemical cardiovascular risk factors after hypertensive pregnancy disorders: a systematic review and meta-analysis. Obstet Gynecol Surv 2012;67:793-809. doi:10.1097/OGX.0b013e31827682fc

15 Kramer MS. The epidemiology of adverse pregnancy outcomes: an overview. J Nutr 2003;133(Suppl 2):1592S-6S. doi:10.1093/ jn/133.5.1592S

16 Hauspurg A, Ying W, Hubel CA, Michos ED, Ouyang P. Adverse pregnancy outcomes and future maternal cardiovascular disease. Clin Cardiol 2018;41:239-46. doi:10.1002/clc.22887

17 Mascarenhas MN, Flaxman SR, Boerma T, Vanderpoel S, Stevens GA. National, regional, and global trends in infertility prevalence since 1990: a systematic analysis of 277 health surveys. PLoS Med 2012;9:e1001356. doi:10.1371/journal.pmed.1001356

18 Anderson SA, Barry JA, Hardiman PJ. Risk of coronary heart disease and risk of stroke in women with polycystic ovary syndrome: a systematic review and meta-analysis. Int J Cardiol 2014:176:486-7. doi:10.1016/j.ijcard.2014.06.079

19 Mu F, Rich-Edwards J, Rimm EB, Spiegelman D, Missmer SA. Endometriosis and risk of coronary heart disease. Circ Cardiovasc Qual Outcomes 2016;9:257-64. doi:10.1161/ CIRCOUTCOMES.115.002224

20 Liou TH, Wu CW, Hao WR, Hsu MI, Liu JC, Lin HW. Risk of myocardial infarction in women with pelvic inflammatory disease. Int J Cardiol 2013;167:416-20. doi:10.1016/j.ijcard.2012.01.006

21 Lidegaard $\varnothing$, Løkkegaard E, Jensen A, Skovlund CW, Keiding N. Thrombotic stroke and myocardial infarction with hormonal contraception. N Engl J Med 2012;366:2257-66. doi:10.1056/ NEJMoa1111840

22 Lavery JA, Friedman AM, Keyes KM, Wright ID, Ananth CV. Gestational diabetes in the United States: temporal changes in prevalence rates between 1979 and 2010. BJOG 2017;124:804-13. doi:10.1111/1471-0528.14236
23 Zhang F, Dong L, Zhang CP, et al. Increasing prevalence of gestational diabetes mellitus in Chinese women from 1999 to 2008. Diabet Med 2011:28:652-7. doi:10.1111/j.1464-5491.2010.03205x

24 Ananth CV, Keyes KM, Wapner RJ. Pre-eclampsia rates in the United States, 1980-2010: age-period-cohort analysis. BM/ 2013:347:f6564. doi:10.1136/bmi.f6564

25 Auger N, Luo ZC, Nuyt AM, et al. Secular trends in preeclampsia incidence and outcomes in a large Canada database: a longitudinal study over 24 years. Can J Cardiol 2016;32:987.e15-23. doi:10.1016/j.cjca.2015.12.011

26 Ray JG, Vermeulen MJ, Schull MJ, Redelmeier DA. Cardiovascular health after maternal placental syndromes (CHAMPS): populationbased retrospective cohort study. Lancet 2005;366:1797-803. doi:10.1016/S0140-6736(05)67726-4

27 Bellamy L, Casas J-P, Hingorani AD, Williams DJ. Pre-eclampsia and risk of cardiovascular disease and cancer in later life: systematic review and meta-analysis. BMJ 2007;335:974. doi:10.1136/ bmj.39335.385301.BE

28 Davis M, Diamond J, Montgomery D, Krishnan S, Eagle K, Jackson E. Acute coronary syndrome in young women under 55 years of age: clinical characteristics, treatment, and outcomes. Clin Res Cardiol 2015;104:648-55. doi:10.1007/s00392-015-0827-2

29 Grand'Maison S, Pilote L, Schlosser K, Stewart DJ, Okano M, Dayan N. Clinical features and outcomes of acute coronary syndrome in women with previous pregnancy complications. Can J Cardiol 2017;33:1683-92. doi:10.1016/i.cjca.2017.08.025

30 Nasir K, Michos ED, Blumenthal RS, Raggi P. Detection of highrisk young adults and women by coronary calcium and National Cholesterol Education Program Panel III guidelines. J Am Coll Cardiol 2005;46:1931-6. doi:10.1016/j.jacc.2005.07.052

31 Michos ED, Nasir K, Braunstein JB, et al. Framingham risk equation underestimates subclinical atherosclerosis risk in asymptomatic women. Atherosclerosis 2006;184:201-6. doi:10.1016/j. atherosclerosis.2005.04.004

32 Bairey Merz CN, Andersen H, Sprague E, et al. Knowledge, attitudes, and beliefs regarding cardiovascular disease in women: the Women's Heart Alliance [correction in: J Am Coll Cardiol 2017;70:1106-07]. J Am Coll Cardiol 2017;70:123-32. doi:10.1016/j.jacc.2017.05.024

33 Haug EB, Horn J, Markovitz AR, et al. Association of conventional cardiovascular risk factors with cardiovascular disease after hypertensive disorders of pregnancy: analysis of the Nord-Trøndelag Health Study. JAMA Cardiol 2019;4:628-35. doi:10.1001/ jamacardio.2019.1746

34 Khot UN, Khot MB, Bajzer CT, et al. Prevalence of conventional risk factors in patients with coronary heart disease. JAMA 2003;290:898904. doi:10.1001/jama.290.7.898

35 Borges LSR, Biondi-Zoccai G. Understanding umbrella review of the cardiovascular research. Int J Cardiovasc Sci. 2016;29:500-3. doi:10.5935/2359-4802.20160066

36 Griffith RJ, Alsweiler J, Moore AE, et al. Interventions to prevent women from developing gestational diabetes mellitus: an overview of Cochrane Reviews. Cochrane Database Syst Rev 2020;6:CD012394

37 Roberge S, Nicolaides K, Demers S, Hyett J, Chaillet N, Bujold E. The role of aspirin dose on the prevention of preeclampsia and fetal growth restriction: systematic review and meta-analysis. Am J Obstet Gynecol 2017;216:110-120.e6. doi:10.1016/j.ajog.2016.09.076

38 Pundir J, Charles D, Sabatini L, et al. Overview of systematic reviews of non-pharmacological interventions in women with polycystic ovary syndrome. Hum Reprod Update 2019;25:243-56. doi:10.1093/ humupd/dmy045

39 Ortega A, Lopez-Briz E, Fraga-Fuentes MD. From qualitative reviews to umbrella reviews. In: Umbrella Reviews. Springer International Publishing, 2016:21-41 doi:10.1007/978-3-319-25655-9 3

40 Haddaway NR, Land M, Macura B. "A little learning is a dangerous thing": A call for better understanding of the term 'systematic review' Environ Int 2017;99:356-60. doi:10.1016/i.envint.2016.12.020

41 Lee E, Dobbins M, Decorby K, McRae L, Tirilis D, Husson H. An optimal search filter for retrieving systematic reviews and meta-analyses. BMC Med Res Methodol 2012;12:51. doi:10.1186/1471-2288-12-51

42 Aromataris E, Fernandez R, Godfrey C, Holly C, Khalil H, Tungpunkom P. Methodology for JBI umbrella reviews. Joanna Briggs Inst Rev Man, 2014:1-34.

43 AMSTAR. Assessing the methodological quality of systematic reviews. https://amstar.ca/Amstar_Checklist.php

44 Shea BJ, Reeves BC. Wells G, et al. AMSTAR 2: a critical appraisal tool for systematic reviews that include randomised or non-randomised studies of healthcare interventions, or both. BMJ 2017;358:j4008. doi:10.1136/bmj.j4008

45 Pieper D, Antoine S-L, Mathes T, Neugebauer EAM, Eikermann M. Systematic review finds overlapping reviews were not mentioned in every other overview. J Clin Epidemiol 2014;67:368-75. doi:10.1016/j.jclinepi.2013.11.007

46 Smith V, Devane D, Begley CM, Clarke M. Methodology in conducting a systematic review of systematic reviews of 
healthcare interventions. BMC Med Res Methodol 2011;11:15. doi:10.1186/1471-2288-11-15

47 Senn SJ. Overstating the evidence: double counting in metaanalysis and related problems. BMC Med Res Methodol 2009;9:10. doi:10.1186/1471-2288-9-10

48 Shojania KG, Sampson M, Ansari MT, Ji J, Doucette S, Moher D. How quickly do systematic reviews go out of date? A survival analysis. Ann Intern Med 2007;147:224-33. doi:10.7326/0003-4819-147-4200708210-00179

49 Bougioukas KI, Liakos A, Tsapas A, Ntzani E, Haidich A-B. Preferred reporting items for overviews of systematic reviews including harms checklist: a pilot tool to be used for balanced reporting of benefits and harms. J Clin Epidemiol 2018;93:9-24. doi:10.1016/j. jclinepi.2017.10.002

50 Pollock M, Fernandes RM, Newton AS, Scott SD, Hartling L. A decision tool to help researchers make decisions about including systematic reviews in overviews of reviews of healthcare interventions. Syst Rev 2019;8:29. doi:10.1186/s13643-018-0768-8

51 Pollock M, Fernandes RM, Newton AS, Scott SD, Hartling L. The impact of different inclusion decisions on the comprehensiveness and complexity of overviews of reviews of healthcare interventions. Syst $\operatorname{Rev}$ 2019;8:18. doi:10.1186/s13643-018-0914-3

52 Garner P, Hopewell S, Chandler J, et al, Panel for updating guidance for systematic reviews (PUGs). When and how to update systematic reviews: consensus and checklist. BMJ 2016;354:i3507. doi:10.1136/bmj.i3507

53 Chung M, Newberry SJ, Ansari MT, et al. Two methods provide similar signals for the need to update systematic reviews. J Clin Epidemiol 2012;65:660-8. doi:10.1016/j.jclinepi.2011.12.004

54 Ahmadzai N, Newberry SJ, Maglione MA, et al. A surveillance system to assess the need for updating systematic reviews. Syst Rev 2013;2:104. doi:10.1186/2046-4053-2-104

55 Roach REJ, Helmerhorst FM, Lijfering WM, Stijnen T, Algra A, Dekkers OM. Combined oral contraceptives: the risk of myocardial infarction and ischemic stroke. Cochrane Database Syst Rev 2015;(8):CD011054. doi:10.1002/14651858.CD011054. pub2

56 Peragallo Urrutia R, Coeytaux RR, McBroom AJ, et al. Risk of acute thromboembolic events with oral contraceptive use: a systematic review and meta-analysis. Obstet Gynecol 2013;122:380-9. doi:10.1097/AOG.0b013e3182994c43

57 Muka T, Oliver-Williams C, Kunutsor S, et al. Association of age at onset of menopause and time since onset of menopause with cardiovascular outcomes, intermediate vascular traits, and all-cause mortality: a systematic review and meta-analysis. JAMA Cardiol 2016;1:767-76. doi:10.1001/jamacardio.2016.2415

58 Gong D, Sun J, Zhou Y, Zou C, Fan Y. Early age at natural menopause and risk of cardiovascular and all-cause mortality: a meta-analysis of prospective observational studies. Int J Cardiol 2016;203:115-9. doi:10.1016/j.ijcard.2015.10.092

59 Tao X-Y, Zuo A-Z, Wang J-Q, Tao F-B. Effect of primary ovarian insufficiency and early natural menopause on mortality: a metaanalysis. Climacteric 2016;19:27-36. doi:10.3109/13697137.201 5.1094784

60 Grandi SM, Filion KB, Yoon S, et al. Cardiovascular disease-related morbidity and mortality in women with a history of pregnancy complications. Circulation 2019;139:1069-79. doi:10.1161/ CIRCULATIONAHA.118.036748

61 Wu P, Haththotuwa R, Kwok CS, et al. Preeclampsia and future cardiovascular health: a systematic review and meta-analysis. Circ Cardiovasc Qual Outcomes 2017;10:e003497. doi:10.1161/ CIRCOUTCOMES.116.003497

62 Kramer CK, Campbell S, Retnakaran R. Gestational diabetes and the risk of cardiovascular disease in women: a systematic review and meta-analysis. Diabetologia 2019;62:905-14. doi:10.1007/ s00125-019-4840-2

63 Li J, Song C, Li C, Liu P, Sun Z, Yang X. Increased risk of cardiovascular disease in women with prior gestational diabetes: A systematic review and meta-analysis. Diabetes Res Clin Pract 2018;140:324-38. doi:10.1016/j.diabres.2018.03.054

64 Wu P, Gulati M, Kwok CS, et al. Preterm delivery and future risk of maternal cardiovascular disease: a systematic review and meta-analysis. J Am Heart Assoc 2018;7:e007809. doi:10.1161/ JAHA.117.007809

65 Robbins CL, Hutchings Y, Dietz PM, Kuklina EV, Callaghan WM. History of preterm birth and subsequent cardiovascular disease: a systematic review. Am J Obstet Gynecol 2014;210:285-97. doi:10.1016/j. ajog.2013.09.020

66 Zhao L, Zhu Z, Lou H, et al. Polycystic ovary syndrome (PCOS) and the risk of coronary heart disease (CHD): a meta-analysis. Oncotarget 2016;7:33715-21. doi:10.18632/oncotarget.9553

67 Xu Z, Li Y, Tang S, Huang X, Chen T. Current use of oral contraceptives and the risk of first-ever ischemic stroke: A meta-analysis of observational studies. Thromb Res 2015;136:52-60. doi:10.1016/j. thromres.2015.04.021
68 Gilbert EW, Tay CT, Hiam DS, Teede HJ, Moran LJ. Comorbidities and complications of polycystic ovary syndrome: An overview of systematic reviews. Clin Endocrinol (Oxf) 2018;89:683-99. doi:10.1111/cen.13828

69 Hopmans T-EJP, van Houten C, Kasius A, et al. [Increased risk of type II diabetes mellitus and cardiovascular disease after gestational diabetes mellitus: a systematic review]. Ned Tijdschr Geneeskd 2015;159:A8043.

70 Ramezani Tehrani F, Amiri M, Behboudi-Gandevani S, BidhendiYarandi R, Carmina E. Cardiovascular events among reproductive and menopausal age women with polycystic ovary syndrome: a systematic review and meta-analysis. Gynecol Endocrinol 2019;0:1-12.

71 Xu Z, Yue Y, Bai J, et al. Association between oral contraceptives and risk of hemorrhagic stroke: a meta-analysis of observational studies. Arch Gynecol Obstet 2018;297:1181-91. doi:10.1007/s00404018-4723-7

72 Glisic M, Shahzad S, Tsoli S, et al. Association between progestinonly contraceptive use and cardiometabolic outcomes: A systematic review and meta-analysis. Eur J Prev Cardiol 2018;25:1042-52. doi:10.1177/2047487318774847

73 Tepper NK, Whiteman MK, Marchbanks PA, James AH, Curtis KM. Progestin-only contraception and thromboembolism: A systematic review. Contraception 2016;94:678-700. doi:10.1016/j. contraception.2016.04.014

74 Sheikh HU, Pavlovic J, Loder E, Burch R. Risk of stroke associated with use of estrogen containing contraceptives in women with migraine: a systematic review. Headache 2018;58:5-21. doi:10.1111/ head.13229

75 Tepper NK, Whiteman MK, Zapata LB, Marchbanks PA, Curtis KM. Safety of hormonal contraceptives among women with migraine: A systematic review. Contraception 2016;94:630-40. doi:10.1016/j. contraception.2016.04.016

76 Chen X, Liu Y, Sun X, et al. Age at menarche and risk of all-cause and cardiovascular mortality: a systematic review and dose-response meta-analysis. Menopause 2018;26:670-6. doi:10.1097/ GME.0000000000001289

77 Charalampopoulos D, McLoughlin A, Elks CE, Ong KK. Age at menarche and risks of all-cause and cardiovascular death: a systematic review and meta-analysis. Am J Epidemiol 2014;180:29 40. doi:10.1093/aje/kwu113

78 Prentice P, Viner RM. Pubertal timing and adult obesity and cardiometabolic risk in women and men: a systematic review and meta-analysis. Int J Obes (Lond) 2013;37:1036-43. doi:10.1038/ ijo.2012.177

79 Tepper NK, Dragoman MV, Gaffield ME, Curtis KM. Nonoral combined hormonal contraceptives and thromboembolism: a systematic review. Contraception 2017;95:130-9. doi:10.1016/j. contraception.2016.10.005

80 Dragoman M, Curtis KM, Gaffield ME. Combined hormonal contraceptive use among women with known dyslipidemias: a systematic review of critical safety outcomes. Contraception 2016;94:280-7. doi:10.1016/j. contraception.2015.08.002

81 Horton LG, Simmons KB, Curtis KM. Combined hormonal contraceptive use among obese women and risk for cardiovascular events: A systematic review. Contraception 2016;94:590-604. doi:10.1016/i.contraception.2016.05.014

82 Tanis BC, van den Bosch MAAJ, Kemmeren JM, et al. Oral contraceptives and the risk of myocardial infarction. N Engl J Med 2001:345:1787-93 doi:10.1056/NEIMoa003216

83 Gronich N, Lavi I, Rennert G. Higher risk of venous thrombosis associated with drospirenone-containing oral contraceptives: a population-based cohort study. CMAI 2011;183:E1319-25. doi:10.1503/cmaj.110463

84 Curtis KM, Mohllajee AP, Martins SL, Peterson HB. Combined oral contraceptive use among women with hypertension: a systematic review. Contraception 2006;73:179-88. doi:10.1016/j. contraception.2005.08.005

85 Zhou Y, Wang X, Jiang Y, et al. Association between polycystic ovary syndrome and the risk of stroke and all-cause mortality: insights from a meta-analysis. Gynecol Endocrinol 2017;33:904-10. doi:10.1080/ 09513590.2017.1347779

86 Cheang KI, Nestler JE, Futterweit W. Risk of cardiovascular events in mothers of women with polycystic ovary syndrome. Endocr Pract 2008;14:1084-94. doi:10.4158/EP.14.9.1084

87 Bolijn R, Onland-Moret NC, Asselbergs FW, van der Schouw YT. Reproductive factors in relation to heart failure in women: a systematic review. Maturitas 2017;106:57-72. doi:10.1016/j. maturitas.2017.09.004

88 Dayan N, Filion KB, Okano M, et al. Cardiovascular risk following fertility therapy: systematic review and meta-analysis. J Am Coll Cardiol 2017;70:1203-13. doi:10.1016/j.jacc.2017.07.753

89 Lv H, Wu H, Yin J, Qian J, Ge J. Parity and cardiovascular disease mortality: a dose-response meta-analysis of cohort studies. Sci Rep 2015;5:13411. doi:10.1038/srep13411 
90 Li W, Ruan W, Lu Z, Wang D. Parity and risk of maternal cardiovascular disease: A dose-response meta-analysis of cohort studies. Eur J Prev Cardiol 2019;26:592-602. doi:10.1177/2047487318818265

91 Nguyen B, Jin K, Ding D. Breastfeeding and maternal cardiovascular risk factors and outcomes: A systematic review. PLoS One 2017:12:e0187923 doi:10.1371/journal.pone.0187923

92 Stuebe AM, Michels KB, Willett WC, Manson JE, Rexrode K, Rich-Edwards JW. Duration of lactation and incidence of myocardial infarction in middle to late adulthood. Am J Obstet Gynecol 2009;200:138.e1-8. doi:10.1016/j.ajog.2008.10.001

93 Schwarz EB, Ray RM, Stuebe AM, et al. Duration of lactation and risk factors for maternal cardiovascular disease. Obstet Gynecol 2009;113:974-82. doi:10.1097/01. AOG.0000346884.67796.ca

94 Gallagher LG, Davis LB, Ray RM, et al. Reproductive history and mortality from cardiovascular disease among women textile workers in Shanghai, China. Int J Epidemiol 2011;40:1510-8. doi:10.1093/ $\mathrm{ije} /$ dyr134

95 Natland Fagerhaug T, Forsmo S, Jacobsen GW, Midthjell K, Andersen LF, Ivar Lund Nilsen T. A prospective population-based cohort study of lactation and cardiovascular disease mortality: the HUNT study. BMC Public Health 2013;13:1070. doi:10.1186/1471-2458-131070

96 Roeters van Lennep JE, Heida KY, Bots ML, Hoek A, collaborators of the Dutch Multidisciplinary Guideline Development Group on Cardiovascular Risk Management after Reproductive Disorders. Cardiovascular disease risk in women with premature ovarian insufficiency: a systematic review and meta-analysis. Eur J Prev Cardiol 2016:23:178-86, doi:10.1177/2047487314556004

97 Muka T, Oliver-Williams C, Colpani V, et al. Association of vasomotor and other menopausal symptoms with risk of cardiovascular disease: a systematic review and meta-analysis. PLoS One 2016;11:e0157417. doi:10.1371/journal.pone.0157417

98 Oliver-Williams CT, Heydon EE, Smith GCS, Wood AM. Miscarriage and future maternal cardiovascular disease: a systematic review and meta-analysis. Heart 2013;99:1636-44. doi:10.1136/ heartjnl-2012-303237

99 Brouwers L, van der Meiden-van Roest AJ, Savelkoul C, et al. Recurrence of pre-eclampsia and the risk of future hypertension and cardiovascular disease: a systematic review and meta-analysis. BJOG 2018;125:1642-54. doi:10.1111/1471-0528.15394

100 Freibert SM, Mannino DM, Bush H, Crofford LJ. The association of adverse pregnancy events and cardiovascular disease in women 50 years of age and older. J Womens Health (Larchmt) 2011;20:287-93. doi:10.1089/jwh.2010.2097

101 Savitz DA, Danilack VA, Elston B, Lipkind HS. Pregnancy-induced hypertension and diabetes and the risk of cardiovascular disease, stroke, and diabetes hospitalization in the year following delivery. Am J Epidemiol 2014;180:41-4. doi:10.1093/aje/kwu118

102 Heida KY, Velthuis BK, Oudijk MA, et al, Dutch Guideline Development Group on Cardiovascular Risk Management after Reproductive Disorders. Cardiovascular disease risk in women with a history of spontaneous preterm delivery: a systematic review and meta-analysis. Eur J Prev Cardiol 2016;23:253-63. doi: $10.1177 / 2047487314566758$

103 Ranthe MF, Andersen EAW, Wohlfahrt J, Bundgaard H, Melbye $\mathrm{M}$, Boyd HA. Pregnancy loss and later risk of atherosclerotic disease. Circulation 2013;127:1775-82. doi:10.1161/ CIRCULATIONAHA.112.000285

104 Kharazmi E, Fallah M, Luoto R. Miscarriage and risk of cardiovascular disease. Acta Obstet Gynecol Scand 2010;89:284-8. doi:10.3109/00016340903380758

105 Kharazmi E, Dossus L, Rohrmann S, Kaaks R. Pregnancy loss and risk of cardiovascular disease: a prospective population-based cohort study (EPIC-Heidelberg). Heart 2011;97:49-54. doi:10.1136/ hrt.2010.202226

106 Pell JP, Smith GCS, Walsh D. Pregnancy complications and subsequent maternal cerebrovascular events: a retrospective cohort study of 119,668 births. Am J Epidemiol 2004;159:336-42. doi:10.1093/ aje/kwh064

107 Tobias DK, Stuart JJ, Li S, et al. Association of history of gestational diabetes with long-term cardiovascular disease risk in a large prospective cohort of US women. JAMA Intern Med 2017;177:173542. doi:10.1001/jamainternmed.2017.2790

108 Daly B, Toulis KA, Thomas N, et al. Increased risk of ischemic heart disease, hypertension, and type 2 diabetes in women with previous gestational diabetes mellitus, a target group in general practice for preventive interventions: a population-based cohort study [correction in: PLoS Med 2019;16:e1002881]. PLoS Med 2018;15:e1002488. doi:10.1371/journal.pmed.1002488

109 Carr DB, Utzschneider KM, Hull RL, et al. Gestational diabetes mellitus increases the risk of cardiovascular disease in women with a family history of type 2 diabetes. Diabetes Care 2006;29:2078-83. doi: $10.2337 /$ dc05-2482
110 Goueslard K, Cottenet J, Mariet AS, et al. Early cardiovascular events in women with a history of gestational diabetes mellitus. Cardiovas Diabetol 2016;15:15. doi:10.1186/s12933-016-0338-0

111 Nguyen B, Gale J, Nassar N, Bauman A, Joshy G, Ding D. Breastfeeding and cardiovascular disease hospitalization and mortality in parous women: evidence from a large Australian cohort study. J Am Heart Assoc 2019;8:e011056. doi:10.1161/JAHA.118.011056

112 Rajaei S, Rigdon J, Crowe S, Tremmel J, Tsai S, Assimes TL. Breastfeeding duration and the risk of coronary artery disease. J Womens Health (Larchmt) 2019;28:30-6. doi:10.1089/ jwh. 2018.6970

113 Jacobson LT, Hade EM, Collins TC, et al. Breastfeeding history and risk of stroke among parous postmenopausal women in the women's health initiative. J Am Heart Assoc 2018;7:e008739. doi:10.1161/ JAHA.118.008739

114 Kirkegaard H, Bliddal M, Støvring H, et al. Breastfeeding and later maternal risk of hypertension and cardiovascular disease - the role of overall and abdominal obesity. Prev Med 2018;114:140-8. doi:10.1016/i.ypmed.2018.06.014

115 Peters SA, van der Schouw YT, Wood AM, et al. Parity, breastfeeding and risk of coronary heart disease: a pan-European case-cohort study [correction in: Eur J Prev Cardiol 2017;24:NP1]. Eur J Prev Cardiol 2016:23:1755-65 doi:10.1177/2047487316658571

116 Peters SAE, Yang L, Guo Y, et al. Breastfeeding and the risk of maternal cardiovascular disease: a prospective study of 300000 Chinese women. J Am Heart Assoc 2017;6:e06081. doi:10.1161/ IAHA.117.006081

117 McClure CK, Catov JM, Ness RB, Schwarz EB. Lactation and maternal subclinical cardiovascular disease among premenopausal women. Am J Obstet Gynecol 2012;207:46.e1-8. doi:10.1016/j. ajog.2012.04.030

118 Gunderson EP, Quesenberry CPJr, Ning X, et al. Lactation duration and midlife atherosclerosis. Obstet Gynecol 2015;126:381-90. doi:10.1097/AOG.0000000000000919

119 Azulay CE, Pariente G, Shoham-Vardi I, Kessous R, Sergienko R, Sheiner E. Maternal anemia during pregnancy and subsequent risk for cardiovascular disease. J Matern Fetal Neonatal Med 2015;28:1762-5. doi:10.3109/14767058.2014.971743

120 Chen PC, Tseng TC, Hsieh JY, Lin HW. Association between stroke and patients with pelvic inflammatory disease: a nationwide populationbased study in Taiwan. Stroke 2011;42:2074-6. doi:10.1161/ STROKEAHA.110.612655

121 Lykke JA, Langhoff-Roos J. First trimester bleeding and maternal cardiovascular morbidity. Eur J Obstet Gynecol Reprod Biol 2012;164:138-41. doi:10.1016/j.ejogrb.2012.06.003

122 Rosendaal NTA, Pirkle CM. Age at first birth and risk of later-life cardiovascular disease: a systematic review of the literature, its limitation, and recommendations for future research. BMC Public Health 2017:17:627. doi:10.1186/s12889-017-4519-x

123 Sterne IAC, Sutton AJ, Ioannidis JPA, et al. Recommendations for examining and interpreting funnel plot asymmetry in meta-analyses of randomised controlled trials. BMJ 2011;343:d4002. doi:10.1136/ bmi.d4002

124 FSRH Clinical Guideline. Combined hormonal contraception (January 2019, amended July 2019) - Faculty of Sexual and Reproductive Healthcare. 2019. https://www.fsrh.org/standards-and-guidance/ documents/combined-hormonal-contraception

125 Sacco S, Merki-Feld GS, Egidius KL, et al, European Headache Federation (EHF) and the European Society of Contraception and Reproductive Health (ESC). Hormonal contraceptives and risk of ischemic stroke in women with migraine: a consensus statement from the European Headache Federation (EHF) and the European Society of Contraception and Reproductive Health (ESC) [correction in: J Headache Pain 2018;19:81]. J Headache Pain 2017;18:108. doi:10.1186/s10194-017-0815-1

126 United Nations, Department of Economic and Social Affairs, Population Division (2019). Contraceptive use by method 2019: Data Booklet (ST/ESA/SER.A/435). https://www.un.org/development/ desa/pd/sites/www.un.org.development.desa.pd/files/files/ documents/2020/Jan/un 2019 contraceptiveusebymethod databooklet.pdf

127 de Groot PCM, Dekkers OM, Romijn JA, Dieben SWM, Helmerhorst FM. PCOS, coronary heart disease, stroke and the influence of obesity: a systematic review and meta-analysis. Hum Reprod Update 2011;17:495-500. doi:10.1093/humupd/dmr001

128 Collins P, Rosano G, Casey C et al. Management of cardiovascular risk in the perimenopausal women: a consensus statement of European cardiologists and gynecologists. Climacteric 2007;10:508-26. doi:10.1080/13697130701755213

129 Mosca L, Benjamin EJ, Berra K, et al. Effectiveness-based guidelines for the prevention of cardiovascular disease in women--2011 update: a guideline from the American Heart Association. Circulation 2011:123:1243-62. doi:10.1161/ CIR.0b013e31820faaf8 
130 European Society of Human Reproduction and Embryology. Management of women with premature ovarian insufficiency: Guideline on the management of premature ovarian insufficiency. 2015. https://www.eshre.eu/-/media/sitecore-files/Guidelines/POI/ ESHRE-guideline_POI-2015_FINAL_11122015.pdf?la=en\&hash= 4956225FEC25B0A0752F79EDEAD1A3D4237D1568

131 Piepoli MF, Hoes AW, Agewall S, et al, ESC Scientific Document Group. 2016 European guidelines on cardiovascular disease prevention in clinical practice: The Sixth Joint Task Force of the European Society of Cardiology and Other Societies on Cardiovascular Disease Prevention in Clinical Practice (constituted by representatives of 10 societies and by invited experts). Developed with the special contribution of the European Association for Cardiovascular Prevention and Rehabilitation (EACPR). Eur Heart J 2016;37:2315-81. doi:10.1093/ eurheartj/ehw106

132 Arnett DK, Blumenthal RS, Albert MA, et al. 2019 ACC/AHA guideline on the primary prevention of cardiovascular disease. Circulation 2019;CIR0000000000000678.

133 Bushnell C, McCullough LD, Awad IA, et al, American Heart Association Stroke Council, Council on Cardiovascular and Stroke Nursing, Council on Clinical Cardiology, Council on Epidemiology and Prevention, Council for High Blood Pressure Research. Guidelines for the prevention of stroke in women: statement for healthcare professionals from the American Heart Association/American Stroke Association [corrections in: Stroke 2014:45:e214, e95]. Stroke 2014:45:1545-88. doi:10.1161/01. str.0000442009.06663.48

134 Heida KY, Bots ML, de Groot CJ, et al. Cardiovascular risk management after reproductive and pregnancy-related disorders: a Dutch multidisciplinary evidence-based guideline. Eur J Prev Cardiol 2016;23:1863-79. doi:10.1177/2047487316659573

135 Oliver-Williams C, Lo C, Lo A, et al. 108 Future cardiovascular disease risk for women with a history of gestational hypertension: a systematic review and meta-analysis. Heart 2019;105(Suppl 6):A89

136 Belbasis L, Savvidou MD, Kanu C, Evangelou E, Tzoulaki I. Birth weight in relation to health and disease in later life: an umbrella review of systematic reviews and meta-analyses. BMC Med 2016;14:147. doi:10.1186/s12916-016-0692-5

137 Mahendru AA, Everett TR, McEniery CM, Wilkinson IB, Lees CC. Cardiovascular function in women with recurrent miscarriage, pre-eclampsia and/or intrauterine growth restriction. J Matern Fetal Neonatal Med 2013;26:351-6. doi:10.3109/14767058.2012.733 774

138 Smith GC, Wood AM, Pell JP, Hattie J. Recurrent miscarriage is associated with a family history of ischaemic heart disease: a retrospective cohort study. BJOG 2011;118:557-63. doi:10.1111/ j.1471-0528.2010.02890.x

139 Bonnar J. Coagulation effects of oral contraception. Am J Obstet Gynecol 1987;157:1042-8. doi:10.1016/S0002-9378(87) 80129-1

140 Gambacciani M, Ciaponi M, Cappagli B, De Simone L, Orlandi R, Genazzani AR. Prospective evaluation of body weight and body fat distribution in early postmenopausal women with and without hormonal replacement therapy. Maturitas 2001;39:125-32. doi:10.1016/S0378-5122(01)00194-3

141 Ozegowska K, Pawelczyk L. Cardiometabolic risk in patients with polycystic ovary syndrome. Ginekol Pol 2015;86:840-8 doi:10.17772/gp/59131
142 Fraser A, Nelson SM, Macdonald-Wallis C, et al. Associations of pregnancy complications with calculated cardiovascular disease risk and cardiovascular risk factors in middle age: the Avon Longitudinal Study of Parents and Children. Circulation 2012;125:1367-80. doi:10.1161/CIRCULATIONAHA.111.044784

143 Stöckl D, Meisinger C, Peters A, et al. Age at menarche and its association with the metabolic syndrome and its components: results from the KORA F4 study. PLoS One 2011;6:e26076. doi:10.1371/ journal.pone.0026076

144 Lindheim SR, Buchanan TA, Duffy DM, et al. Comparison of estimates of insulin sensitivity in pre- and postmenopausal women using the insulin tolerance test and the frequently sampled intravenous glucose tolerance test. / Soc Gynecol Investig 1994;1:150-4. doi:10.1177/107155769400100210

145 Rappelli A. Hypertension and obesity after the menopause. I Hypertens Suppl 2002;20:S26-8.

146 Natland ST, Nilsen TIL, Midthjell K, Andersen LF, Forsmo S. Lactation and cardiovascular risk factors in mothers in a populationbased study: the HUNT-study. Int Breastfeed ) 2012;7:8. doi:10.1186/1746-4358-7-8

147 Kalantaridou SN, Naka KK, Papanikolaou E, et al. Impaired endothelial function in young women with premature ovarian failure: normalization with hormone therapy. J Clin Endocrinol Metab 2004;89:3907-13. doi:10.1210/jc.2004-0015

148 Skilton MR, Sérusclat A, Begg LM, Moulin P, Bonnet F. Parity and carotid atherosclerosis in men and women: insights into the roles of childbearing and child-rearing. Stroke 2009;40:1152-7. doi:10.1161/STROKEAHA.108.535807

149 Jasper R, Skelding K. Cardiovascular disease risk unmasked by pregnancy complications. Eur J Intern Med 2018;57:1-6. doi:10.1016/j.ejim.2018.07.020

150 Ehrenthal DB, Catov JM. Importance of engaging obstetrician/ gynecologists in cardiovascular disease prevention. Curr Opin Cardiol 2013;28:547-53. doi:10.1097/HCO.0b013e328364298e

151 British Heart Foundation. Heart and circulatory disease statistics 2019. Stat Compend 2019;2019:94-6.

152 NICE. Contraception - assessment. 2019. https://cks.nice.org.uk/ topics/contraception-assessment/\#!scenarioRecommendation:13

153 Williams D. Pregnancy: a stress test for life. Curr Opin Obstet Gynecol 2003;15:465-71. doi:10.1097/00001703-20031200000002

154 Fraser A, Catov JM, Lawlor DA, Rich-Edwards JW. Pregnancy characteristics and women's cardiovascular health. In: Handbook of life course health development. Springer International Publishing, 2018: 145-65. doi:10.1007/978-3-319-47143-3_8

155 Isiadinso I, Wenger NK. Do we need a different approach to assess cardiovascular risk in women?US Cardiol Rev 2017;11:5 doi:10.15420/usc.2016:8:2

156 Baart SJ, Dam V, Scheres LJ), et al, CREW consortium. Cardiovascular risk prediction models for women in the general population: $\mathrm{A}$ systematic review. PLoS One 2019;14:e0210329. doi:10.1371/ journal.pone.0210329

157 Rich-Edwards JW, Fraser A, Lawlor DA, Catov JM. Pregnancy characteristics and women's future cardiovascular health: an underused opportunity to improve women's health?Epidemiol Rev 2014:36:57-70. doi:10.1093/epirev/mxt006

Web appendix: Appendices 